\title{
Review Article \\ Genetic Dissection of the Physiological Role of Skeletal Muscle in Metabolic Syndrome
}

\author{
Nobuko Hagiwara \\ Department of Internal Medicine, Division of Cardiovascular Medicine, University of California, Davis, CA 95616, USA \\ Correspondence should be addressed to Nobuko Hagiwara; nhagiwara@ucdavis.edu
}

Received 18 May 2014; Accepted 6 August 2014; Published 19 August 2014

Academic Editor: Hui-Qi Qu

Copyright ( 2014 Nobuko Hagiwara. This is an open access article distributed under the Creative Commons Attribution License, which permits unrestricted use, distribution, and reproduction in any medium, provided the original work is properly cited.

\begin{abstract}
The primary deficiency underlying metabolic syndrome is insulin resistance, in which insulin-responsive peripheral tissues fail to maintain glucose homeostasis. Because skeletal muscle is the major site for insulin-induced glucose uptake, impairments in skeletal muscle's insulin responsiveness play a major role in the development of insulin resistance and type 2 diabetes. For example, skeletal muscle of type 2 diabetes patients and their offspring exhibit reduced ratios of slow oxidative muscle. These observations suggest the possibility of applying muscle remodeling to recover insulin sensitivity in metabolic syndrome. Skeletal muscle is highly adaptive to external stimulations such as exercise; however, in practice it is often not practical or possible to enforce the necessary intensity to obtain measurable benefits to the metabolic syndrome patient population. Therefore, identifying molecular targets for inducing muscle remodeling would provide new approaches to treat metabolic syndrome. In this review, the physiological properties of skeletal muscle, genetic analysis of metabolic syndrome in human populations and model organisms, and genetically engineered mouse models will be discussed in regard to the prospect of applying skeletal muscle remodeling as possible therapy for metabolic syndrome.
\end{abstract}

\section{Introduction}

Are we getting healthier as technology and medicine advance? According to the latest epidemiological study on baby boomers in the United States, unfortunately the answer appears to be "No, we are not" [1]. This study tells us that far more aging baby boomers, compared to the previous generation, are afflicted by lifestyle induced clinical conditions such as hypertension, hypercholesterolemia, type 2 diabetes mellitus, and obesity [1]. Despite these health problems, people are living longer due to medical advances. The steadily increasing life expectancy combined with expanding waist lines presents a daunting challenge for society to maintain a good quality of life in the aging population.

The aforementioned clinical conditions, hypertension, hypercholesterolemia, type 2 diabetes mellitus, and obesity, are all symptomatic components of metabolic syndrome. Metabolic syndrome consists of a heterogeneous, but highly interconnected set of clinical conditions which together lead to a high risk of cardiovascular diseases [2]. The World
Health Organization (WHO) provided a working definition of metabolic syndrome as the combination of one symptom from group 1 (insulin resistance, type 2 diabetes, impaired fasting glucose, impaired glucose tolerance) and two from group 2 (elevated blood pressure $(\geq 140 / 90 \mathrm{mmHg}$ ), dyslipidemia (triglycerides $>1.7 \mathrm{mmol} / \mathrm{L}$ and/or low HDL cholesterol $<0.9 \mathrm{mmol} / \mathrm{L}$ for men and $<1.0 \mathrm{mmol} / \mathrm{L}$ for women), obesity (hip ratio $>0.9$ for men and $>0.85$ for women and/or BMI $>30$ ), or microalbuminuria (urinary albumin excretion rate $\geq 20 \mathrm{mg} / \mathrm{min}$ or albumin/creatinine ratio $\geq 30 \mathrm{mg} / \mathrm{g}$ )) [3] . Active discussions and attempts to update and unify the definitions of metabolic syndrome are still on going. An in depth discussion on the definitions and controversies in this matter can be found here [4]. In the more recent definitions presented by the National Cholesterol Education Program's Adult treatment Panel III report (ATP III), abdominal obesity is used as the primary criterion for metabolic syndrome [2], rather than the presence of insulin resistance which was emphasized by WHO. Despite the different weight placed on clinical criteria, the main culprit for metabolic 
syndrome is the sedentary life style of modern society and its manifestation as obesity [1].

With the complex nature of metabolic syndrome aside, a well-accepted tenet for combating this cluster of clinical conditions is to maintain a healthy weight through physical exercise and a healthy diet. To test the efficacy of using this approach at the population level, a large scale life style intervention study was conducted targeting type 2 diabetes patients and obese/overweight individuals [5]. In spite of the encouraging results at the initial stage of the study, long-term (10 years) intensive life style intervention did not yield a significant improvement over the control group (education in type 2 diabetes only) in terms of the risk of cardiovascular morbidity and mortality [6]. This large scale trial exemplifies the difficulties and challenges to apply life style modifications to treat high risk individuals for type 2 diabetes and cardiovascular diseases. It should also be noted that, in some cases, exercise is not recommended to type 2 diabetes patients because of their cardiovascular and other systemic complications which bar them from physical activities [7]. Because insulin resistance by itself increases the risk of cardiovascular diseases and precedes the development of type 2 diabetes [8], identifying molecular therapeutic targets to improve insulin sensitivity would be a rewarding direction to slow or prevent the onset of type 2 diabetes and manage the cardiovascular risk factors of metabolic syndrome.

Insulin resistance is the result of multiorgan dysfunction of insulin-sensitive tissues such as skeletal muscle, liver, and adipose tissues. Among these, skeletal muscle stands out as the principal organ of glucose uptake. In euglycemic conditions, skeletal muscle accounts for $75-80 \%$ of the glucose uptake in response to insulin stimulation $[9,10]$, and in experimentally induced hyperglycemic conditions, $95 \%$ of whole body insulin-mediated glucose uptake was delivered by skeletal muscle [9]. Because of its significant capacity for glucose uptake, skeletal muscle insulin resistance has a major impact on the development of impaired glucose metabolism in metabolic syndrome and type 2 diabetes. This was clearly demonstrated in a study assessing insulin-mediated glycogen synthesis (an indicator of insulin sensitivity) in lean insulinresistant individuals fed with high-carbohydrate meals; in these individuals, a significant reduction in skeletal muscle glycogen synthesis was observed, whereas no such reduction in liver glycogen synthesis was observed [11]. Instead, the liver exhibited a significant increase in triglyceride accumulation, likely compensating for glycogen synthesis defects in skeletal muscle of the insulin-resistant subjects [11]. These observations suggest that skeletal muscle insulin resistance precedes liver insulin resistance, and the elevated hepatic lipogenesis may simultaneously promote the development of dyslipidemia, another component of metabolic syndrome. Granting the manifestation of insulin resistance is a complex process; it is fair to say that skeletal muscle insulin resistance is a key to initiate pathophysiology of the whole-body insulin resistance and its development into metabolic syndrome and type 2 diabetes.

In this review, I will discuss the genetic bases for skeletal muscle insulin resistance, metabolic syndrome, and type
2 diabetes, summarizing both human genetic association studies and animal model studies. Since the research field of metabolic syndrome is immense, it is not the goal of this review to cover it in its entirety; rather, its focus is to discuss recent discoveries of molecular pathways or genes that are involved in the development of skeletal muscle insulin resistance and metabolic syndrome with respect to physiological characteristics of skeletal muscle and explore future directions in order to apply these discoveries for therapies of metabolic syndrome.

\section{Physiological Characteristics of Skeletal Muscle Fibers and Metabolic Syndrome in Humans}

Skeletal muscle consists of heterogeneous types of fibers displaying a range of contractile speeds and metabolic capacities [12, 13]. Initially, categorization of skeletal muscle was made as red (dark) and white based on the muscle's color [14]. This difference in color stems from the differential abundance in the oxygen-binding protein myoglobin which brings to the muscle a red color [15]. The redder the muscle is, the metabolic capacity of the muscle is more oxidative (more myoglobin); conversely, the paler the muscle is, the muscle is less oxidative and its main metabolic capacity is governed by glycolysis. The metabolic state of a muscle fiber is tightly coupled with its contractile speed which is dictated by the ATPase activity of myosin heavy chain (MyHC). The higher the ATPase activity (ATP hydrolysis rate) of the MyHC head domain, the greater the speed of contraction delivered by the sliding of $\mathrm{MyHC}$ over the actin filament [16]. Oxidative muscle fibers contain slower $\mathrm{MyHC}$ isoforms and a higher amount of mitochondria and thus are fatigue-resistant and optimized for supporting long durations of contractile demands. Glycolytic fibers, on the other hand, contain less mitochondria and faster $\mathrm{MyHC}$ isoforms and thus are fatigue-sensitive and geared towards burst of quick contractile activities [17, 18]. The major components of human skeletal muscle fibers are three types of fibers, type 1 , type $2 \mathrm{~A}$, and type $2 \mathrm{~B}[19,20]$, which largely correspond to slow-oxidative (SO), fast-oxidative/glycolytic (FOG), and fast-glycolytic (FG) gradation of physiological attributes [12, 13, 21]. This heterogeneity in skeletal muscle is the principal basis for the functional adaptability of skeletal muscle, which is termed fiber type plasticity. Skeletal muscle is highly responsive and able to adjust its functionality to environmental demands. Use of skeletal muscle in physical activity as well as disuse of it in inactivity can change the composition of skeletal muscle fibers, thus altering the metabolic capacity of skeletal muscle. Significant to the contemporary sedentary life style, disuse of skeletal muscle induces fiber type shifts from slow-oxidative (SO) towards fast-glycolytic (FG). This SO to FG shift has been reported for a microgravity environment experienced during space flight and in a more day-to-day condition such as bed-rest [2224]. In the muscle disuse conditions, a significant atrophy in SO fibers was also reported [23, 25]. Since SO skeletal muscle shows a greater insulin binding capacity and larger 


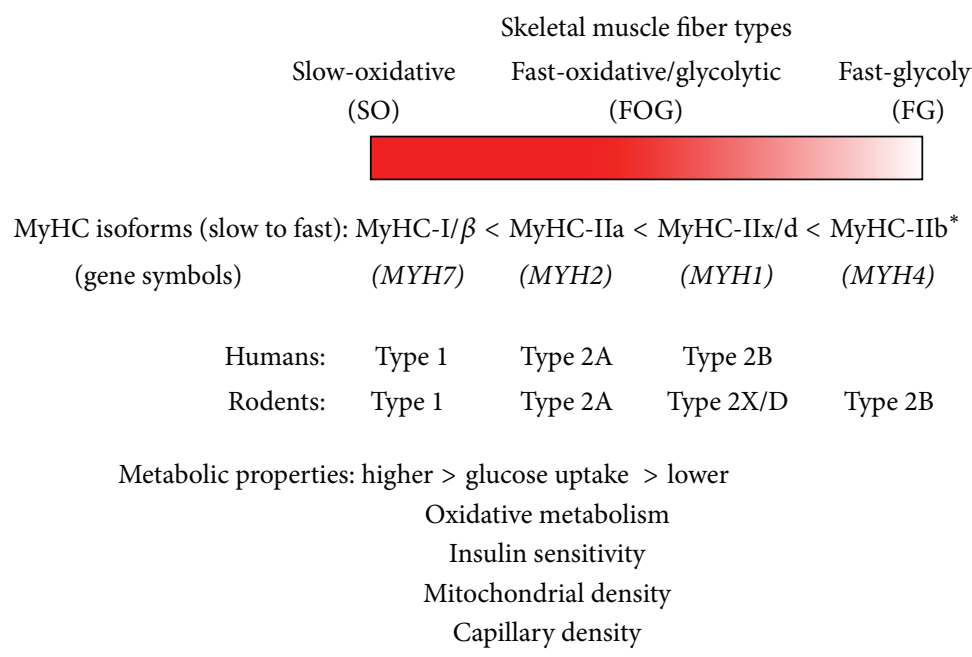

FIGURE 1: The properties of different skeletal muscle fiber types. Contractile and metabolic properties of skeletal muscle fibers are summarized. ${ }^{*}$ The MyHC-IIb isoform is undetected in human skeletal muscle except for laryngeal and extraocular muscles. In humans, type 2B fiber expresses the MyHC-IIx/d isoform. (italic) Gene symbols by HUGO Gene Nomenclature Committee. Fiber type nomenclature based on $\mathrm{MyHC}$ isoform expression is determined by immunohistochemistry using MyHC isoform-specific monoclonal antibodies.

glucose uptake than FG muscle [26-30], this SO to FG shift and loss of SO fibers induced by inactivity has a potentially deleterious effect on glucose homeostasis at the whole-body level.

In sedentary life style-induced conditions such as obesity, metabolic syndrome, and type 2 diabetes, it has been assumed that skeletal muscle would present a similar type of physiological changes as observed in the unweighted muscle, fostering the development of skeletal muscle insulin resistance. This assumption has been verified in reports showing that conditions including insulin resistance, type 2 diabetes, and obesity in humans are associated with reduction in SO muscle fibers and/or oxidative metabolism [31-42]. Furthermore, molecular level studies have demonstrated that, in humans with insulin resistance and type 2 diabetes, expression of oxidative metabolism genes is significantly reduced in a coordinated manner [43-45]. Therefore, both epidemiological and molecular level studies collectively support the notion that reduced SO fiber content and oxidative metabolic capacity are linked with insulin resistance which is an essential component of metabolic syndrome.

Conversely, another characteristic of SO-rich skeletal muscle beneficial for glucose homeostasis is its higher capillary density $[33,35,46-50]$. It has been reported that the degree of glucose tolerance is positively correlated with capillary density in skeletal muscle [49]. The fiber typespecific properties of skeletal muscle discussed in this section are summarized in Figure 1. It is immediately clear that increasing and/or maintaining a higher level of oxidative metabolic capacity contributed by SO muscle fibers through endurance exercise is highly beneficial to prevent metabolic syndrome and to reduce the risk for cardiovascular diseases [51], yet as discussed in the Introduction, achieving this goal in the high risk group for metabolic syndrome and type 2 diabetes patients is extremely difficult. Therefore, exploring effective molecular targets that can be directly manipulated to replicate the beneficial metabolic characteristics of SO skeletal muscle is becoming increasingly more important.

\section{Genetics of Insulin Resistance and Metabolic Syndrome}

3.1. Human Population Studies. As described above, insulin resistance and type 2 diabetes are accompanied with a reduction in SO fibers and/or oxidative metabolic enzyme activities in skeletal muscle. This trend is also reproduced in healthy offspring of type 2 diabetes patients [52-54], indicating that there is a large hereditary component in skeletal muscle fiber type proportion and resulting metabolic conditions. Accordingly, it has been reported that almost $50 \%$ of fiber type phenotype of human skeletal muscle is determined by genetic factors [55]. These reports indicate that the physiological traits critical for maintaining insulin sensitivity and normal glucose metabolism in skeletal muscle are highly heritable; thus sizable portions of metabolic syndrome could be explained by genetic predisposition. In the study of normoglycemic offspring of type 2 diabetes patients, it was shown that impairments of insulin sensitivity and glucose disposal rate preexisted and those individuals developed type 2 diabetes [56], strongly indicating the genetic predisposition effects for the development of insulin resistance in the future. This observation has been independently reproduced in two different ethnic group studies (Finish and Pima Indian) [57, 58].

Genetic predispositions of insulin resistance indicated by epidemiological studies could be manifested at multiple levels of insulin-induced glucose disposal including initial insulin receptor (IR) and insulin receptor substrate (IRS) interactions, the ensuing cascades of kinase activation of their substrates, and translocation of glucose transporters to the cell membrane. To identify genes and/or gene expression 
defects accounting for the observed predisposition of insulin resistance and related deficiencies, multifaceted approaches have been taken. These approaches include family based linkage analysis for monogenic diseases, candidate gene approaches to identify mutations in the insulin pathway genes, genome wide association studies (GWAS) for associated sequence variants with disease risk, gene expression profiling for detecting possibly causal changes in gene expression, and in vitro cell culture and model organism studies to validate the functional contribution of the putative candidate genes (e.g., review in [59]). Since the phenotypes of metabolic syndrome in human population studies are defined at the whole body level, the following section discusses genetic analyses of metabolic syndrome from the epidemiological view, not necessarily focusing on genetic contribution of skeletal muscle metabolic defects.

The challenges of identifying a genetic smoking gun accounting for the heritability of metabolic syndrome are exemplified in the case of single nucleotide polymorphisms (SNPs) associated with the IRS1 (insulin receptor substrate 1). A missense mutation at codon 972 of the IRS1 gene (Glycine to Arginine, G972R) is a highly-investigated coding sequence variant in the IRS1 gene. The IRS1 G972R was originally identified as a coding polymorphism associated with the development of insulin resistance in Danish type 2 diabetes patients ( 86 case and 75 control individuals) through a candidate gene approach [60]. A functional study was later conducted by coexpressing the IR (insulin receptor) and mutant IRS1 proteins in the 32D myeloid progenitor cell line (negative for IR and IRS-1, thus suitable to examine the mutant IRS1 function) to test the effect of the G972R IRS1 protein on cell's responsiveness to insulin [61]. The IRS1 G972R expressing cells exhibited reduced activation of phosphatidylinositol 3-kinase (PI-3 kinase), a target for phosphorylation by IRS1 in the insulin signaling pathway, indicating that the G972R variant could impair insulin sensitivity at the cellular level [60]. However, larger human population case-control studies with different ethnic populations presented mixed results. In a meta-analysis of 35 case-control human population association studies, 32 studies did not show statistically significant association of the G972R variant with the increased risk for type 2 diabetes [62]. In a family-based association study designed to control for population stratification, the IRS1G972R variant again did not show statistically significant association with the metabolic syndrome components, type 2 diabetes, impaired glucose tolerance, and impaired fasting glucose [63].

In more recent years, a major effort has been made to identify single nucleotide sequence variants associated with the components of metabolic syndrome using high density SNP-chips. In one of these GWAS, a noncoding SNP located near the IRS1 gene (rs2943641) was reported to be associated with a slightly elevated risk for type 2 diabetes in French and Danish populations (odds ratio $=1.19, P$ value $=9.28 \times$ $10^{-12}$ ) [64]. When the same SNP was tested in a Han Chinese population, however, no association with type 2 diabetes risk was found (odds ratio $=1.14, P$ value $=0.298$ ) [65] The low odds ratio/small effect size reported for the IRS1
SNP association with type 2 diabetes is a common occurrence in GWAS for complex trait diseases and phenotypes $[59,66,67]$. The difficulties of identifying causal sequence variants (large enough effect size to explain heritable risks) for complex trait diseases could be a built-in nature of the SNPs that have been selected for GWAS. They are relatively common (allele frequency $>5 \%$ in population); thus their effect on the disease phenotype would be accordingly fairly small, albeit statistically significant, because if they were highly deleterious, they would have been eliminated long before by selective pressure [68, 69]. By design, sequence variants found to be associated with metabolic syndrome phenotypes so far all present very modest effect size, too small to explain the strong hereditary nature of metabolic syndrome. Be that as it may, can we explain the heritability of complex diseases by the cumulative effects of multiple sequence variants? Probably so, because interaction studies on a few select sequence variants associated with the risk of type 2 diabetes reported a significant increase in odds ratio when SNPs were paired [70]. However, extending this type of locus to locus interaction analysis to millions of SNPs would be a massive statistical endeavor, requiring an immense number of samples to gain enough statistical power and thus may not be plausible at present time. Other critical issues contributing to the small effect size are the lack of quantitative measurements for the phenotype being studied and biases in choosing populations for GWAS. Since metabolic syndrome is a highly heterogeneous disease, a large bracket classification such as case/control is too arbitrary and would likely dilute the hereditary risk of the associated sequence variants [71]. Also, the majority of GWAS available today are focused on the populations of European descent; therefore, any SNPs found to be associated would likely be skewed by European population-specific genetic architecture, that is, the group-specific linkage disequilibrium block carrying adjacently located sequence and structural variants which are population-specific $[68,72]$. One more important fact to remember is that the overwhelming majority of the SNPs used for GWASs are distantly located from gene coding regions; thus their assignment to candidate genes is not fully reliable [73].

The journey of the IRS1 SNPs to their association with type 2 diabetes illustrates the difficulties and challenges faced in the genetic dissection of complex traits disease in general. In spite of the conceptual and technical biases of GWASs, we are still sitting on a mountain of treasures for genetic information containing risk factors for metabolic syndrome and type 2 diabetes. Would it be possible to identify a key that would unlock the door to high risk genetic factors for metabolic syndrome or even the genetic basis for skeletal muscle insulin resistance? Or, are we still missing some critical pieces of information which would take us out of the labyrinth of association studies? Answers to these questions may not be forth coming anytime soon, but a road to it is being chiseled little by little.

Next generation sequencing technologies have transformed the ways phenotype-genotype correlations are mined, lessening the preconceived biases, and at the same time, massively increasing the speed of data acquisition. In the 
recent years, whole exome sequencing has made it clear that our coding sequences are littered with a far larger number of single nucleotide variations (SNVs) than we have ever expected with probable functional consequences. For example, an exome sequencing study of European- and African-American populations identified over 500,000 SNVs, of which $86 \%$ were rare (minor allele frequency $<0.5 \%$ ) [74]. In the populations studied, it was estimated that each individual genome carried approximately $300 \mathrm{SNV}$ s that could affect protein function and on average, each individual carried 35 nonsense SNVs and was homozygous for at least one of the nonsense mutations [74]. This report could strengthen the hypothesis that rare-to-low-frequency SNVs $(0.5 \%<$ minor allele frequency $<5 \%$ ) with presumably a larger effect size account for a major fraction of heritability in complex trait diseases including metabolic syndrome. This is an attractive hypothesis to explain the lack of heritability in GWAS; however, it has not yet been rigorously tested. One recent study attempted to test this hypothesis by performing whole exome sequencing for 2,000 Danish individuals (half case, half control) seeking rare coding variants with a moderate but sizable effect to account for the heritable risk for type 2 diabetes [75]. Even though their simulation analyses had enough statistical power to find such association (if rare sequence variants had a large enough effect size to account for the disease risk in a modest number, i.e., less than 20 such causal variants), they were not able to find such rare variants [75]. Granted the sample size was relatively small, this result may suggest that, rather than a few causal gene mutations, a culmination of multiple gene mutations with a small effect size would pass the disease phenotype threshold to manifest complex trait diseases.

The population-based studies represented by GWAS illustrate the difficulties in applying population-based data of phenotype to genotype association in order to estimate an individual's risk for complex traits such as metabolic syndrome. The awareness of these difficulties prompted new efforts to analyze an individual's disease risk from the standpoint of genotype to phenotype association, which is termed as Phenome-Wide Association Study (PheWAS) [76-78]. This reverse genetics approach utilizes electronic medical records (EMR), which represents a wide spectrum of human disease phenotypes and/or simply physiological readings provided by laboratories, termed as the human phenome. Individual phenome information is extracted from longitudinal medical histories such as medication, laboratory testing for blood and image testing, physician's notes, and the universal International Classification of Disease (ICD) code [78]. The advantage of this approach is that it stipulates association of a specific genetic variant with clinically defined physiological conditions by assessing effects of individual sequence variants; therefore, interconnected disease etiology could be uncovered [76, 78]. In addition, if detailed quantitative information is available in EMR (e.g., blood pressure and blood glucose levels), it could allow us to assess genotype to phenotype association quantitatively. In the recent systematic PheWAS (3,144 SNPs previously associated with traits by GWAS in 13,835 individuals), $66 \%$ of the prior GWAS associations were replicated (type 2 diabetes was part of them) along with newly identified genotypephenotype associations [77]. As whole genome and exome sequencing becomes less expensive and an increasingly common practice, it would be possible to catalogue rare sequence variants in combination with medical records applicable to PheWAS. Though it is a considerable endeavor, networks of population study bases for PheWAS are emerging [77, 79]. When combined with model organism studies which are discussed below, this genotype-phenotype approach could be extremely powerful for assessing risks and etiology of complex trait diseases including metabolic syndrome in human population.

\subsection{Use of Model Organism in Validating Candidate Genes Identified by Human Population Studies}

3.2.1. Nonmammalian Models-Fruit Flies, Worms, and Zebrafish. Model organisms play critical roles in the functional validation of metabolic syndrome candidate genes and sequence variants identified by GWAS and PheWAS in the human genome. Although only humans can represent the true nature of our physiology and body design, significantly high levels of evolutionary conservations in gene function among invertebrates, nonmammalian vertebrates, and mammals provide invaluable resources to conduct functional assays for the candidate genes.

Fruit flies (Drosophila melanogaster) have been a leading model organism for investigating the genetic regulation of body pattern formation and gene-gene interactions. Their short life cycle, highly efficient mutagenesis as well as genespecific inactivation technologies, and the low cost for breeding provide great advantages as a model system to perform functional studies for multiple candidate genetic loci identified in human population studies. Recently, the recognition of Drosophila as a model system to investigate metabolic syndrome is growing. Importantly, sequences of key molecular components in the mammalian insulin signaling pathway (e.g., IR, IRS, Akt, target of rapamycin (TOR), and secondary messengers) are evolutionarily conserved in Drosophila [8082]. It has also been demonstrated that fruit flies fed a highfat-diet develop obesity and cardiac dysfunction because of the impairment of the insulin signaling pathway [83]. In a recently published study, RNAi knockdown experiments were applied to assess sucrose tolerance in Drosophila in order to validate the functional significance of human candidate genes for metabolic syndrome risks identified in GWAS studies [84]. 83 candidate genes have recognized fruit fly orthologs. Of these, the transcription factors TCF7L2, HHEX, and PPARG induced strong sucrose intolerance when their expression was knocked down [84]. Each of these transcription factors has previously been implicated for their association with type 2 diabetes, confirming their conserved functionality in metabolic homeostasis.

Other invertebrate and nonmammalian organisms are also gaining recognition as models for metabolic syndrome. C. elegans exhibits an insulin-like signaling cascade for the regulation of nutrient storage and has been applied to investigate metabolic defects [85-87]. As described for Drosophila, C. elegans has been also used to functionally 
validate a human candidate gene associated with type 2 diabetes. Aberrant glycosylation of proteins with O-GlcNAC (O-linked $\beta$-N-acetyleglucosamine) is linked to the pathogenesis of type 2 diabetes [88] and a SNP for the O-GlcNAC glucosaminidase MGEA5 was found to be associated with the risk for type 2 diabetes in a Mexican American population study [89]. Knocking out the orthologous O-GlcNAC glucosaminidase in C. elegans, oga-1, demonstrated metabolic and signaling defects resembling human insulin resistance [90].

In addition to Drosophila and C. elegans, zebrafish (Danio rerio) is recently attracting attention as a model to study obesity and metabolic syndrome [91]. Application of zebrafish for metabolic study is appealing because they possess the major organs involved in the development of metabolic syndrome, the pancreas, and insulin-responsive peripheral tissues such as skeletal muscle (slow-twitch and fast twitch), liver, and white adipose tissue. Also, the chambered heart (atria and ventricle) of zebrafish allows us to model cardiomyopathy induced by metabolic challenges. The recent development of TALEN and CRISPR/Cas9 sequence editing technologies $[92,93]$ can significantly expand the capacity of reversegenetics (genotype to phenotype) using zebrafish, increasing their value as a model for metabolic syndrome. In summary, combining the resources discussed here with mouse models as discussed below will propel and expand our ability to identify bona fide gene sequence variants and mutations for metabolic syndrome in humans.

3.2.2. Mouse Models. The mouse is the evolutionarily closest model organism to humans whose genome is readily manipulated. At the DNA level, over $90 \%$ of human and mouse genomes can be aligned as conserved syntenic segments, substantiating the value of mouse models for deciphering molecular mechanisms of complex human diseases which are associated with multiple sequence variants [94]. With the recent data from the ENCODE project, potential biological functions of noncoding DNA sequences that could be relevant to human complex trait diseases have started to be uncovered $[95,96]$. When the noncoding sequence variants are mapped in the syntenic regions that are conserved between mice and humans, it enables researchers to conduct in-depth functional studies using mouse genome manipulation to uncover their functions. The utility of this approach was demonstrated in the case for noncoding SNPs of the FTO (fat mass and obesity associated) gene.

The noncoding SNPs identified in the $47 \mathrm{~kb}$ linkage disequilibrium (LD) block spanning through the first and second introns of the FTO gene are the most consistent and significant associations reported so far for the risk of obesity in humans [97-99]. One of these common variants is also associated with metabolic syndrome and its traits $[100,101]$. Although the exact biological functions of the FTO gene are still unknown [102], transgenic overexpression as well as inactivation of the Fto gene in mice demonstrated that Fto gene expression levels positively correlate with obesity phenotype [103-105]. However, no correlation between FTO expression levels and FTO SNPs has been found in human tissues [106-108], leaving the connection between the FTO SNPs and the effect on obese phenotype unsettled. Since these noncoding FTO SNPs are mapped in the syntenic region between the mouse and human genomes [109], they present an ideal opportunity to apply mouse genome engineering to probe the function of the FTO noncoding region sequence presumably conserved in mice as well.

This approach was employed successfully in a recent report which revealed that the sequence of the common SNPcontaining FTO first intron region is indeed conserved in the mouse Fto gene and functions as an enhancer of the Irx3 gene located a half megabase downstream of the Fto gene [110]. Importantly, the authors found that the SNP associated with obesity risk in humans was also positively correlated with increased expression of IRX3 in human brain, but no such correlation was found for FTO. This result suggested that misregulation of IRX3, but not FTO, is the culprit for human obesity. To functionally validate this discovery, Irx3knockout mice were generated; Irx3 $\mathrm{KO}$ mice were leaner and were protected against a high-fat-diet, showing for first time that Irx3 expression level regulated by the Fto first intron enhancer is the likely cause for obesity risk [110]. This example demonstrates the promise of successfully uncovering biological effects of the sequence variants associated with metabolic syndrome using mouse models. In the next section, I will discuss how mouse models are being utilized to dissect out the possible roles of skeletal muscle in the development of metabolic syndrome and insulin resistance.

\section{Genetic Regulation of Physiological Characteristics in Skeletal Muscle and Their Implications for Metabolic Syndrome}

One of the major insulin-responsive tissues responsible for glucose homeostasis is skeletal muscle. Since skeletal muscle is not a homogeneous tissue, it is important to understand how the various muscle fiber types relate to the overall metabolic state of the organism. Molecular mechanisms of fiber type differentiation and plasticity of mammalian skeletal muscle have been intensively investigated using rodents as a model. The most well-defined classification of skeletal muscle fiber type is by expression of specific myosin heavy chain isoforms, from slowest to fastest, MyHC-I/ $\beta$ (Myh7), MyHCIIa (Myh2), MyHC-IIx/d (Myh1), and MyHC-IIb (Myh4) [111]. MyHC isoform expression corresponds to the degree of oxidative metabolic capacity of the muscle fiber, from the most oxidative to the least oxidative in the order of the slowest to the fastest MyHC isoform [12]. There is some dissimilarity in skeletal muscle physiology between humans and mice though, likely stemming from difference in their body size. First, in humans, MyHC-IIb is expressed only in extraocular and laryngeal muscles, but not in the larger body muscles [112], whereas MyHC-IIb and MyHC-IIx/d express muscles predominate in mice (Figure 1). Secondly, in humans $\mathrm{MyHC}-\mathrm{IIx} / \mathrm{d}$ fibers are least oxidative, whereas in mice, these muscle fibers are highly oxidative [12]. However, because of the evolutionarily conserved organization of muscle fiber type-specific genes and their transcriptional regulation at the 


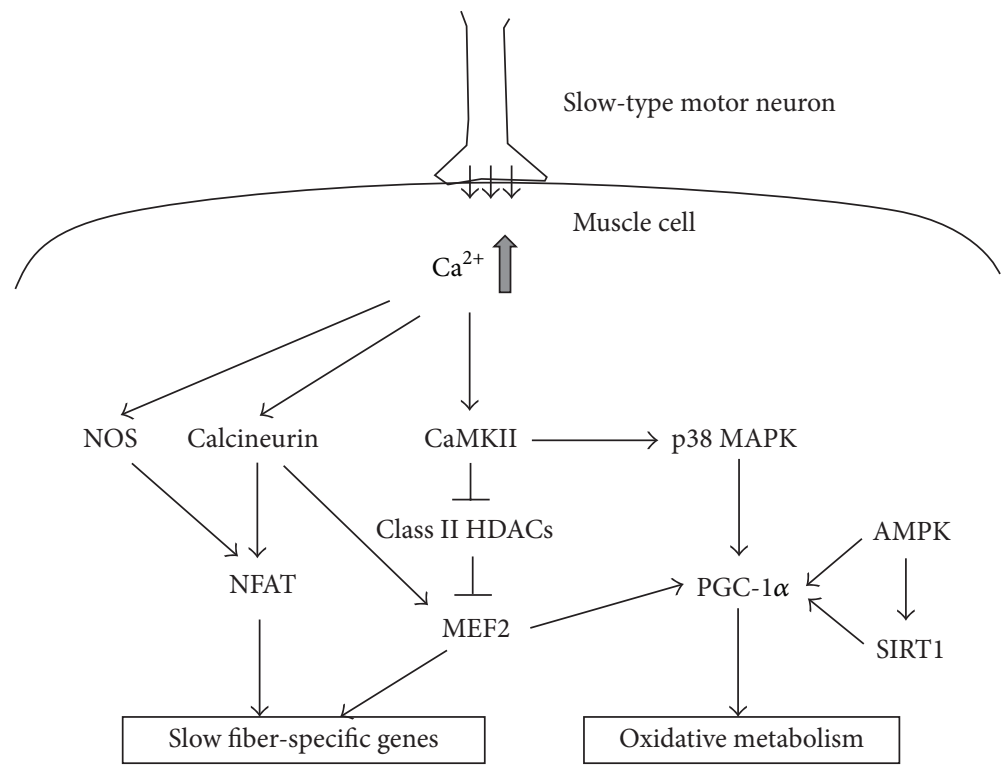

FIGURE 2: Schematic diagram of activation of slow fiber-specific and oxidative metabolic genes in skeletal muscle fiber type plasticity. Intracellular $\mathrm{Ca}^{2+}$ levels are raised by tonic-low frequency (slow type) stimulation. An arrow indicates activation and a bar with a horizontal line indicates suppression. The transcription factors NFAT, Mef2, and PGC-1 $\alpha$ activate transcription of target genes which define fiber type properties.

molecular level between the two species (e.g., the MyHC gene clusters, [113]), the mouse is a highly valuable model system to investigate the molecular mechanisms regulating the determination of physiological properties of human skeletal muscle. In the following section, I will discuss transcriptional regulation of skeletal muscle fiber type-specific properties followed by a discussion on the use of mouse models for identifying therapeutic target genes in metabolic syndrome.

4.1. Molecular Mechanisms of Fiber Type Plasticity in Adult Skeletal Muscle. As discussed earlier, the physiological properties of skeletal muscle, both contractility and metabolic capacity, are highly adaptive to the use and disuse of muscle. Because of the importance of skeletal muscle physiology in the development of insulin resistance (e.g., oxidative metabolism, glucose uptake), remodeling of adult skeletal muscle is emerging as a key area of research in the field of metabolic diseases. In adult skeletal muscle, maintenance and remodeling of contractility and the metabolic capacity of skeletal muscle are largely regulated by electrical input from motor neurons and nutrient conditions as described below.

Corresponding to the slow-twitch and fast-twitch skeletal muscle fiber types, motor neurons vary in their firing patterns, namely, tonic (constant and low frequency-activities) and phasic (a short burst of high frequency-activities) discharge patterns, corresponding to slow and fast type motor neurons, respectively $[114,115]$. Slow oxidative (SO), fast glycolytic (FG), and fast oxidative/glycolytic (FOG) muscle fibers are singly innervated by motor neurons of the matching firing patterns [116]. By mimicking the slow and fast motor neuron firing patterns using electrical stimulation, a shift in $\mathrm{MyHC}$ isoform expression patterns was successfully induced in rat hindlimb muscle [117]. Also in humans, this principle of converting muscle fiber types via electrical stimulation mimicking motor neuron firing patterns was successfully applied to physiologically remodeling skeletal muscle. Chronic low frequency stimulation (CLFS), which delivers electrical stimulation resembling the pattern of motor neurons innervating slow and fatigue resistant (SO) muscle fibers, induced a shift from faster to slower MyHC isoform expression and an increase in oxidative metabolic capacity in human hamstring muscle [118]. To test the efficacy of CLFS as a therapy to improve exercise capacity in humans, congestive heart failure (CHF) patients were treated with CLFS [119]. In this clinical study, CLFS treated patients presented a significant faster to slower shift in MyHC isoform expression and an increase in oxidative enzyme activity which was reflected in improved exercise performance and quality of life of the treated patients compared to control [119]. Since skeletal muscle of CHF patients exhibits a decrease in SO fibers and reduced oxidative metabolic capacity [120] analogous to that of type 2 diabetes $[44,121]$, CLFS has a potential to improve oxidative metabolic capacity of skeletal muscle afflicted by metabolic syndrome, an avenue which, as yet, has not been fully explored. In this light, identifying molecules mediating skeletal muscle fiber type plasticity in response to neural stimulation may also present new targets for therapies of metabolic syndrome patients.

Several signaling molecules and transcription factors have been implicated as mediators to convert the information coded in nerve firing patterns of motor neurons into the instructions to elicit cellular responses in skeletal muscle (Figure 2). Chronic nerve activity of the slow type motor neuron results in an elevated free intracellular calcium concentration, which activates the calcium-calmodulin dependent phosphatase calcineurin [122]. Activation of calcineurin then leads to increased transcription of slow fiber 
type-specific isoform genes in skeletal muscle [123-125]. The nuclear factor of activated T-cells (NFAT) is among the targets activated by calcineurin; dephosphorylation of NFAT by calcineurin prompts nuclear translocation of NFAT and leads to expression of slow fiber type-specific genes $[12,123$, 126-131] and repression of fast fiber type-specific genes [130]. It should be noted that the nuclear translocation of NFAT is induced by electrical stimulation mimicking slow-type motor neuron firing (i.e., CLFS), but not by fast-type firing pattern [131], indicating discrete regulation of muscle fiber type by nerve impulse.

In addition to motor neuron firing patterns, NFAT nuclear translocation is also controlled by nitric oxide (NO), a signaling molecule whose synthesis is regulated by nitric oxide synthase (NOS) [132]. NOS activation in skeletal muscle (endothelial NOS and neuronal NOS in particular) is regulated by its interaction with calcium-calmodulin [133]. This interaction couples the NO signaling pathway with the elevated intracellular calcium levels induced by slow-type motor neuron stimulation. Indeed, it has been shown that chronic low frequency stimulation (CLFS) induces nNOS expression in skeletal muscle [134]. Therefore, it is conceivable that the $\mathrm{NO}$ and calcineurin pathways work collectively to promote fast to slow muscle fiber type conversion in response to slow motor neuron activity. This was demonstrated in rat models by simultaneous treatment of fast-type limb muscle with CLFS and the NOS inhibitor L-NAME [135]. As discussed above, CLFS typically induces NFAT nuclear translocation and subsequent transcriptional activation of slow fiber typespecific isoform genes; however, in the presence of L-NAME, dephosphorylation and nuclear translocation of NFAT was suppressed; therefore, despite the treatment with CLFS, faster to slower shift in MyHC isoform expression did not occur [135]. This report indicates that part of the fast to slow conversion of skeletal muscle fiber type is controlled by two parallel $\mathrm{Ca}^{2+}$ sensor pathways, calcineurin and NOS which converge at the regulation of NFAT activity (Figure 2).

What is the relation of this result to metabolic syndrome patients? In human skeletal muscle, NOS expression is the highest in FOG (fast oxidative/glycolytic) fibers and the more oxidative the fiber, the higher the level of NOS expression [136], suggesting that NOS activity levels may be correlated with the oxidative capacity of FOG muscle fibers. In skeletal muscle of type 2 diabetes patients with decreased oxidative metabolic capacity [43-45], both basal and insulin-stimulated levels of NOS activity are notably reduced [137]. Additionally, a deficiency in insulin-stimulated NOS activation is highly correlated with the severity of insulin resistance [137]. Taken together, successful activation of the NO signaling pathway to regain the diminished oxidative metabolic capacity in skeletal muscle will likely have a beneficial effect on mending insulin resistance in metabolic syndrome.

In addition to the $\mathrm{Ca}^{2+} /$ calmodulin-dependent phosphatase calcineurin, $\mathrm{Ca}^{2+} /$ calmodulin-dependent kinases (CaMK) have been shown to function as mediators of skeletal muscle remodeling induced by nerve stimulation (Figure 2). CaMKII can sense oscillations in $\mathrm{Ca}^{2+}$ concentration through autophosphorylation of the $\mathrm{Thr}^{287}$ residue, leading to its enzymatic activation $[138,139]$. For CaMKII activation in skeletal muscle, cellular $\mathrm{Ca}^{2+}$ concentration needs to be elevated above the basal level by muscle contraction [140]. In humans, exercise has been shown to significantly increase CaMKII activity in skeletal muscle $[141,142]$. Taken together, these observations suggest that CaMKII is as equally vital of a $\mathrm{Ca}^{2+}$ concentration sensor in muscle as calcineurin. How does activation of CaMKII lead to physiological remodeling of skeletal muscle? It is proposed that CaMKII assists transcriptional activation of slow fiber type-specific isoform genes by NFAT through activation of a NFAT partner transcription factor, the myocyte enhancer factor 2 (MEF2) [143, 144]. The transcriptional activity of MEF2 is controlled by class II histone deacetylases (HDACs), which directly bind to MEF2 and suppress MEF2's activity [145-148]. MEF2 activation occurs when CaMKII phosphorylates HDACs, leading to dissociation of HDAC from MEF2. The release of the bound HDAC allows MEF2 to activate transcription of its target genes and induce differentiation and fiber type shifting of skeletal muscle $[149,150]$. The activation of MEF2 by CaMKII appears to be regulated by firing patterns of motor neurons, because electrostimulation of muscle fibers with tonic-low frequency (slow type) induced CaMKII activation, which was coupled with nuclear efflux of HDAC4 and consequent activation of MEF2 [151]. It should be noted that MEF2 activation is controlled by calcineurin as well $[143,144]$. Multiple $\mathrm{Ca}^{2+}$ sensors activated by tonic motor neuron stimulation regulate the slow fiber type, phenotype, in a synergistic manner, likely providing a tight control on remodeling of skeletal muscle. These sensor molecules therefore constitute candidates for inducing fast to slow fiber type shifting of skeletal muscle which could be beneficial for patients of metabolic syndrome.

The shifting towards slower fiber types in skeletal muscle is presumed to be beneficial to type 2 diabetes or metabolic syndrome mainly because of the coupled increase in oxidative metabolic capacity and glucose uptake, traits that are highly correlated with insulin sensitivity [152]. One of the key transcriptional regulators of oxidative metabolism is the peroxisome proliferator-activated receptor- $\gamma(\operatorname{PPAR} \gamma)$ coactivator $1 \alpha$ (PGC-1 $\alpha$ ) (Figure 2) [153-156]. It has been shown that endurance exercise increases PGC- $1 \alpha$ expression levels at both the mRNA and protein levels [157-159]. A likely $\mathrm{Ca}^{2+}$ sensing pathway that increases PGC-1 $\alpha$ expression level to coordinate oxidative metabolic capacity with muscle contractility is the CaMKII-p38 mitogen-activated protein kinases (p38 MAPK) axis $[160,161]$. The p38 MAPK family $(\alpha, \beta, \gamma$, and $\delta)$ plays a significant role in differentiation [162], energy expenditure [163], and insulin-induced glucose uptake in skeletal muscle [164]. It has also been shown using transgenic mice that muscle-specific activation of p38 activity leads to increased expression of PGC- $1 \alpha$ and oxidative metabolic enzymes [160]. A more recent report demonstrating that p38 activation is induced by CaMKII, followed by upregulation of PGC- $1 \alpha$ and mitochondrial biogenesis [161], has provided evidence linking this $\mathrm{Ca}^{2+}$ sensor molecule with PGC- $1 \alpha$ induced oxidative metabolism. This result suggests 
that the motor neuron activity-induced metabolic adaptation employs separate downstream effectors (such as p38 MAPK and PGC- $1 \alpha$ ) from those involved in a fast to slow shift in fiber-type-specific isoform gene expression. This view is supported by muscle specific knockout mice of p38 and PGC- $1 \alpha$. Inactivation of either p38 $\gamma$ (not p $38 \alpha$ and p38 $\beta$ ) or PGC- $1 \alpha$ in skeletal muscle abrogated metabolic adaptation through mitochondrial biogenesis but did not affect contractile adaptation of the fast to slow shift in fiber typespecific isoform expression $[165,166]$. Although experimental separation of metabolic and contractile adaptation of skeletal muscle to nerve activation is possible, convergence of the two regulatory axes at multiple effector molecules integrates two adaptive responses into a highly coordinated process (Figure 2).

The relevance of PGC- $1 \alpha$ in the metabolic adaptation of skeletal muscle can be seen in type 2 diabetes patients and their asymptomatic relatives as well as obese mice and obese insulin resistant rat model, all of which demonstrated a clear reduction of PGC- $1 \alpha$ expression in skeletal muscle (an average of $~ 30 \%$ ) [43, 44, 167, 168]. Supporting the efficacy of therapeutic intervention, modest overexpression of PGC- $1 \alpha$ in rat skeletal muscle $(30-40 \%$ of muscle fibers were transfected by a PGC- $1 \alpha$ transgene) induced a beneficial physiological change by increasing oxidative metabolic enzyme and insulin-induced glucose uptake levels [169].

In addition to the nerve activity-based $\mathrm{Ca} 2^{+}$signaling pathways, nutrient levels within cells have a significant effect on the metabolic state of skeletal muscle. The most essential molecule to sustain cellular energy level is ATP. The primary energy sensor for the fluctuation of ATP levels is AMPactivated protein kinase (AMPK) which is activated by an increased AMP to ATP ratio in the cell [170]. AMPK manages cellular energy homeostasis by modulating activities of a vast number of mediator molecules. In skeletal muscle, PGC- $1 \alpha$ is one of the AMPK targets; PGC- $1 \alpha$ is activated through direct phosphorylation by AMPK [171] as well as deacetylation by the SIRT1 deacetylase $[172,173]$ induced by AMPK [174] (Figure 2). In the intact skeletal muscle, contraction-induced increases in AMP to ATP ratio induced AMPK activation, underlining the importance of exercise to maintain high levels of oxidative metabolism and glucose uptake [175]. However, it is also possible to pharmacologically activate PGC- $1 \alpha$ by means of activating AMPK by AICAR and SIRT1 using resveratrol [176-178]. Since maintaining a sufficient level of physical activity to gain health benefits in sedentary individuals is often difficult in implementation, pharmacological activation of PGC- $1 \alpha$ and relating metabolic regulators could be a promising treatment option for metabolic syndrome patients.

4.2. Developmental Regulation of Skeletal Muscle Fiber Type Specification. In humans, it has been shown that heredity plays a major role in determining fiber type distribution and metabolic activities of skeletal muscle in each individual $[55,179,180]$. The observations that the healthy offspring of type 2 diabetes patients show lower ratios of SO muscle fiber content in skeletal muscle [52-54], a phenotypic trait of type 2 diabetes skeletal muscle, validates the significance of genetic factors in determining the physiological property of skeletal muscle. These reports imply that a predetermined condition of skeletal muscle may influence an individual's predisposition to the development of metabolic syndrome and may also affect the capacity of postnatal muscle remodeling. Unlike fiber type plasticity, which is primarily regulated by slow and fast type firing patterns of motor neurons, initial fiber type specification during embryonic muscle development is initiated without significant input from motor neurons [181]. Nerve input gains control over muscle fiber type development only in later fetal stages [182]. To support the presence of nerve-independent mechanisms of fiber type specification, it has been shown that calcineurin, one of the main nerve activity-dependent regulators of slow fiber gene expression in adult muscle, is dispensable for the development of slow type fibers in embryonic skeletal muscle [183]. Therefore, a blueprint for skeletal muscle fiber type distribution is most likely designed by muscle-intrinsic factors different from those regulating muscle fiber type plasticity in adult muscle. The identification of factors regulating embryonic muscle fiber type differentiation is beginning to reveal the developmental pathways which are responsible for an individual's predisposition to metabolic syndrome.

Development of skeletal muscle fibers in mammalian embryos occurs in waves and fiber type differentiation is controlled in a sequential manner $[184,185]$. The first wave, primary myogenesis, generates myofibers committed to express the slow MyHC-I/ $\beta$ isoform $[181,186]$. The second wave, secondary myogenesis, generates myofibers whose default state is fast MyHC expressing fibers, but muscle progenitor cells generated in this lineage are receptive to external cues and are able to adapt their final phenotype to the local environment [187]. In mice and humans, primary myogenesis and secondary myogenesis occur around embryonic days 11-15 and 15-birth [188, 189] and gestation weeks 6-8 and 8-18 [190], respectively. Satellite cells, which facilitate growth, remodeling, and regeneration of adult skeletal muscle [191], also exhibit predetermined MyHC expression patterns. Namely, mouse satellite cells associated with slow or fast muscle fibers preferentially differentiate into slow or fast type myotubes in culture, respectively [192]. This default state of MyHC isoform expression has been replicated in regenerating rat skeletal muscle, indicating that the future fiber type phenotypes of satellite cells are intrinsically determined by the types of muscle fibers with which they are associated [193]. Therefore, uncovering the mechanisms determining the developmental competence of fetal myoblasts as well as satellite cells will aid our effort in remodeling skeletal muscle.

It has been shown that formation of fast type myofibers during embryogenesis requires the transcription factor Sryrelated HMG box protein 6 (Sox6) [194, 195]. During embryonic limb muscle development in mice, Sox6 is expressed in fast secondary myofibers (negative for MyHC- $\beta / \mathrm{I}$ ), but not in MyHC- $\beta /$ I positive slow myofibers [196]. These results indicate that the function of Sox6 in skeletal muscle development is to suppress slow fiber type-specific isoform gene expression in myofibers differentiating into fast fibers (Figure 3). This is indeed the case as shown by muscle-specific Sox6 inactivation 


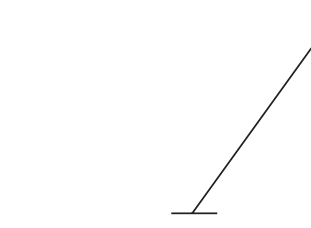

Slow fiber-specific genes miR-499(in Myh7b intron)

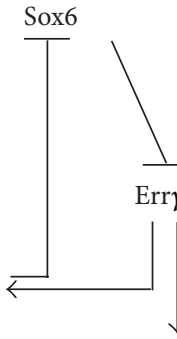

Oxidative metabolism
Six $1 / 4$

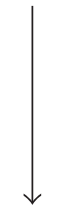

Fast fiber-specific genes glycolytic metabolism

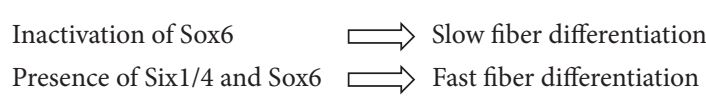

FiguRE 3: Schematic diagram of skeletal muscle fiber type differentiation during embryogenesis. Sox6 functions as a suppressor of slow fiberspecific genes and Sixl/4 function as activators of fast fiber-specific genes. An arrow indicates activation and a bar with a horizontal line indicates suppression.

$[196,197]$ and ChIP-seq which detected Sox6 binding targets in the genome [196]. Inactivation of Sox6 in embryonic skeletal muscle led to a significant expansion in MyHC-I/ $\beta$ expressing slow oxidative fibers at the expense of MyHCIIb expressing fast fibers $[196,197]$. This developmental shift in fiber type ratio is directly regulated at the transcriptional level by Sox 6 which binds to the regulatory sequence of slow fiber type-specific genes and suppresses their transcription [196]. Along with the fast to slow shift in contractile gene expression, Sox6 KO muscle was more fatigue resistant [197], indicating the presence of coordinated adaptation towards oxidative metabolism when Sox6 is inactivated.

How is this coordination of slow contractile and oxidative metabolic traits achieved in developing skeletal muscle in the absence of well-established motor neuron innervation? Since PGC- $1 \alpha$ expression was not reliably upregulated in Sox6 KO skeletal muscle $[196,197]$ and calcineurin was shown to be unnecessary for embryonic slow fiber differentiation [183], oxidative metabolic adaptation in Sox6 $\mathrm{KO}$ muscle during development should be independent of the calcineurin-PGC$1 \alpha$ pathway. A likely candidate is estrogen-related receptor $\gamma($ ERR $\gamma /$ ESRRG $)$ which activates oxidative metabolism and mitochondrial biogenesis in a PCG- $1 \alpha$ independent manner $[198,199]$. ERR $\gamma$ is among the Sox6 target genes identified by ChIP-seq [196] and is upregulated in Sox6 KO skeletal muscle (Hagiwara, unpublished data) (Figure 3). Therefore, coordinated expression of slow contractile proteins and oxidative metabolic enzymes in fetal skeletal muscle could be orchestrated by the balance of Sox6 and ERR $\gamma$ expression. In this regulatory pathway, the microRNA miR-499 is also involved, buttressing the regulatory circuit. The miR-499 is a member of MyomiRs (myogenic microRNAs) and downregulates Sox6 expression level in skeletal muscle [200, 201]. It has been reported that ERR $\gamma$ upregulates miR-499 synthesis [202]. This ERR $\gamma$-miR-499 interface may take part to form a Sox6-ERR $\gamma$ feedback loop for orchestrating skeletal muscle phenotype during development (Figure 3).

The importance of Sox6 in determining the fiber type distribution and metabolic traits during muscle development raises the possibility that Sox6 expression levels may have a link to the predisposition towards metabolic syndrome. Indeed, several GWAS studies demonstrated that SOX6 is associated with elevated blood pressure and obesity risk in multiple ethnic populations [203-206]. These observations suggest that sequence polymorphisms, as well as mutations which affect the SOX6-ERR $\gamma$-miR499 regulatory loop, could increase individuals' susceptibility to metabolic syndrome.

For the fast muscle fiber-development program, the sine oculis homeobox 1/eyes absent 1 (Six1/Eyel) transcriptional complex plays an important role [207]. It has been shown that the Sixl/Eyel complex is found to be accumulated in the nuclei of fast-twitch fibers in adult and activates transcription of the glycolytic enzyme Aldolase A gene. Electroporation of Six1/Eyel expression vectors in a slow muscle resulted in upregulation of fast contractile and glycolytic metabolic enzyme genes, indicating their role in coordinating fast fiber type phenotype [207]. Subsequently, using double KO mice for the Sixl and Six 4 genes, it has been shown that Six genes are necessary for fast glycolytic muscle fibers during fetal development (Figure 3) [208]. Interestingly, in Six1/4 DKO fetal skeletal muscle, Sox6 appeared to be localized more in the cytoplasm, suggesting that there is a crosstalk between Six and Sox6 regulatory pathways during fetal skeletal muscle development [208]. Fiber type and metabolic specification of skeletal muscle during development is still not well understood. Uncovering regulatory networks determining physiological properties of skeletal muscle as fetus develops would likely present diagnostic markers for predisposition towards metabolic syndrome and possibly new therapeutic targets for preventing the future development of metabolic syndrome.

4.3. Use of Genetically Engineered Mice in Search of Therapeutic Targets for Metabolic Syndrome and Obesity. As discussed above, ratios of SO muscle fibers, oxidative metabolic capacity, and glucose uptake are reduced in type 2 diabetic patients and obese individuals. The epidemiological studies do not distinguish whether this physiological change in muscle is 
a cause or simply an effect of the conditions induced by metabolic syndrome. Studies using genetically engineered mice, although somewhat artificial, are allowing us to tease out a web of causes and effects regarding this issue.

One of the main questions being asked is whether genetically increasing SO fibers in skeletal muscle can improve or even prevent the deleterious metabolic conditions caused by metabolic syndrome. To test this, several key genes regulating the activity-induced FG to SO transition in skeletal muscle were inactivated in muscle for the proof of concept and overexpressed in muscle to assess their beneficial effect. Three of the major regulatory molecules described above, namely, calcineurin, PGC- $1 \alpha$ and their partner proteins, and AMPK, will be discussed below.

Calcineurin is necessary to maintain slow muscle fibers in adult skeletal muscle [183]. Accordingly, transgenic overexpression of a constitutively active form of calcineurin in mouse skeletal muscle results in a significant increase in expression of the GLUT4 glucose transporter and insulin receptor [209]. Due to elevated expression of these genes, the calcineurin transgenic mice exhibited elevated insulinstimulated glucose uptake and glycogen synthesis levels in the muscle, converting them into SO types, and additionally, increasing resistance to high-fat induced glucose intolerance [209]. This result demonstrates that the activation of calcineurin in skeletal muscle could be a viable strategy for treating insulin resistance in metabolic syndrome.

PGC- $1 \alpha$ functions as a central regulator of mitochondrial biogenesis and cellular metabolism as a cofactor of multiple nuclear receptor transcription factors [210]. Adult mice overexpressing PGC- $1 \alpha$ in a muscle-specific manner exhibit an increase in oxidative metabolism [154] and enhanced exercise performance [211]. Skeletal muscle of muscle-specific PGC-1 $\alpha$ $\mathrm{KO}$ mice, conversely, presented an increase in FG fibers at the expense of SO and FOG fibers and a decrease in voluntary physical activity [212], indicating PGC- $1 \alpha$ 's importance in maintaining physiological properties of adult skeletal muscle. The main function of PGC- $1 \alpha$ as a regulator of exerciseinduced metabolic adaptation has been confirmed using muscle-specific PGC-1 $\alpha$ KO mice; in these mice, exerciseinduced mitochondrial biogenesis was defective, whereas the faster to slower transition in contractility was not affected [165]. PGC- $1 \alpha$ transgenic mice were then used to test whether overexpression of PGC- $1 \alpha$ in skeletal muscle provides a beneficial effect on whole body metabolism when challenged by obesity-inducing conditions. The answer was no. The muscle-specific PGC-1 $\alpha$ TG mice (driven by the muscle creatin kinase promoter) show a $600 \%$ increase in PGC- $1 \alpha$ mRNA expression and a 2.4-fold increase in mitochondrial density in muscle and also maintain similar body weight and fat mass as wild type mice when fed on regular chow diet [213]. When the PGC- $1 \alpha$ transgenic mice were fed a high fat diet, they were not only unprotected from high fat diet-induced obesity but also exhibited decreased insulin sensitivity [213]. It appeared that the high fat diet-induced insulin resistance of PGC- $1 \alpha$ transgenic muscle was caused by elevated levels of muscle lipid accumulation, since the expression of genes involved in fatty acid intake and storage was significantly upregulated in these mice [213], and a high level of lipid accumulation in muscle is linked to insulin resistance [214].

Interestingly, this lipid-overload phenotype of the PGC$1 \alpha$ TG skeletal muscle is very similar to that of PPAR $\alpha$ overexpressing cardiac and skeletal muscle $[215,216]$. PPAR $\alpha$ is one of the nuclear receptor transcription factors for which PGC-1 $\alpha$ works as a cofactor [210]. Both musclespecific PPAR $\alpha$ transgenic mice exhibited increased fatty acid uptake coupled with decreased glucose uptake and metabolic phenotype of diabetes [215, 216]. It should be noted, however, that expression of PGC- $1 \alpha$ is downregulated in PPAR $\alpha$ overexpressing muscles $[215,216]$, suggesting the existence of some compensation mechanisms. Though there is some promise in manipulating the PGC- $1 \alpha$ cofactor regulating pathways as therapeutic targets for metabolic syndrome, caution should be taken to find a right range of activation for each component so as not to disrupt the delicate balance of the pathways.

One exception to this could be PPAR $\delta$. PPAR $\delta$ is a predominant PPAR receptor isoform in skeletal muscle and, together with PGC- $1 \alpha$, induces expression of fatty acid oxidative enzymes [217]. Pharmacological activation of PPAR $\delta$ in mice with GW5015 showed protection against diet-induced obesity and improved insulin sensitivity [218]. This beneficial effect of PPAR $\delta$ activation was reproduced by muscle-specific overexpression of a constitutively active form of PPAR $\delta$ [219]. These mice displayed increased physical endurance and protection from obesity as well as improved insulin sensitivity when fed with high-fat diet [219]. In these mice, PGC-1 $\alpha$ expression levels were unchanged [219]. These observations suggest that among the PGC- $1 \alpha$ regulatory pathways, PPAR $\delta$ so far presents the best application potential as a therapeutic target for metabolic syndrome.

Activation of AMPK affects a wide range of downstream targets, including elevation of fatty acid uptake and oxidation, increased mitochondrial biogenesis, and stimulation of glucose uptake, through both transcriptional and posttranslational changes [170]. Because these effects are expected to be beneficial to improve metabolic conditions of metabolic syndrome patients, AMPK is one of the most sought-after therapeutic targets for type 2 diabetes [220]. Indeed, a commonly used type 2 diabetes drug, metformin, activates AMPK to induce its beneficial effects [221, 222].

To gain direct evidence for the importance of AMPK in skeletal muscle metabolism and exercise capacity, $\mathrm{KO}$ mice for multiple AMPK subunits ( $\alpha, \beta$, and $\gamma$-subunits) have been generated. Muscle-specific $\alpha 1 / \alpha 2$ double KO mice showed reduced endurance exercise capacity and mitochondrial respiration rates but retained mitochondrial density and contraction-induced glucose uptake in skeletal muscle [223]. Reflecting the role of AMPK in regulating PGC- $1 \alpha$ expression $[171,174]$, PGC- $1 \alpha$ mRNA levels were significantly reduced in the DKO mice, which is likely the cause of the exercise intolerance seen in these mice [223]. Muscle-specific AMPK $\beta 1 / \beta 2$ double $\mathrm{KO}$ mice had a similar but more severe phenotype; they presented reduced capacity for voluntary and forced exercise, significant reduction in mitochondrial content, and contraction-induced glucose uptake [224]. In contrast to the AMPK $\beta 1 / \beta 2 \mathrm{DKO}$ mice, $\gamma 3$ subunit $\mathrm{KO}$ mice 
exhibited a more specific phenotype, mainly deficiency in glycogen synthesis after exercise [225], reflecting the highlevel expression of the $\gamma 3$ subunit in glycolytic fibers [226]. Fittingly, mice overexpressing a gain-of-function form of $\gamma 3$ subunit mutant showed enhanced postexercise glycogen synthesis [227]. Together, these reports underline the central role of AMPK in regulating glucose and lipid metabolism in skeletal muscle, hence its utility as a therapeutic target for metabolic syndrome [228].

In studies using rodents, pharmacological activation of AMPK has been shown to be beneficial. In mice, double treatment of AICAR and GW1516 (PPAR $\delta$ agonist) mimicked the benefits of exercise and resulted in a reduction in epididymal fat mass [177]. To test its efficacy for treating the conditions associated with insulin resistance, obese Zucker rats were treated with the AMPK activator AICAR for 7 weeks ( $0.5 \mathrm{mg} / \mathrm{g}$ body weight) [229]. Treated animals showed a significant decrease in fasting plasma glucose, insulin, triglyceride, and free fatty acid levels, increased HDL levels, and demonstrated normalized glucose tolerance and lowered systolic blood pressure [229]. Also AICAR treatment enhanced the expression of the GLUT4 glucose transporter with resulting insulin induced glucose uptake primarily in fast glycolytic muscle [229]. AICAR treatment of a mouse model for type 2 diabetes, ob/ob mice (leptin mutant homozygous mice) provided mixed results; oneweek treatment with AICAR (1 mg/g body weight) corrected hyperglycemia and improved glucose tolerance; however, it also induced higher levels of free fatty acids and triglycerides [230]. This deleterious effect with AICAR could be due to a high dose or genetic conditions caused by the leptin mutation. When high-fat fed obese wild type mice were treated with a lower dose of AICAR $(0.15 \mathrm{mg} / \mathrm{g}$ body weight) for 5 weeks, these animals showed significant improvement in glucose tolerance and insulin sensitivity accompanied with reduced adipose inflammation [231]. These results indicate complex and unexpected biological effects could be induced by pharmacological activation of AMPK.

Stimulating glycogen synthesis in skeletal muscle could improve insulin sensitivity. The efficacy of this strategy to combat against diet-induced obesity and associated metabolic defects was verified by using transgenic mice. These mice were engineered to induce overexpression of AKT1 (a serine/threonine kinase, also known as protein kinase B) specifically in fast glycolytic muscle which resulted in significant hypertrophy of muscle FG fibers [232]. The FG muscle AKT overexpression reduced body weight along with fat mass and improved insulin-induced glucose uptake in mice fed a high fat diet [232]. This result suggests that augmentation of FG muscle fibers would provide another promising therapeutic target for improving whole-body metabolism of metabolic syndrome patients.

\section{Epigenetics and Metabolic Syndrome}

An emerging field in the study of metabolic syndrome is epigenetic regulation of the disease. Epigenetics lies between the genotype (DNA sequence) and the phenotype (manifestation of traits), by inducing heritable changes without altering the DNA sequence. These heritable changes include DNA methylation and posttranslational modifications of histone molecules [233]. It is thought that epigenetic changes have a significant share in the etiology of complex diseases including metabolic syndrome by affecting the age of onset, quantitative nature of complex trait disease, and genetic predisposition of individuals in relation to the environment [234]. It has been shown that monozygotic twins who share a common genotype accumulate differential DNA methylation patterns and histone modifications during their life time, which in turn alters their gene expression profile [235]. This observation underscores the importance of the epigenetic contribution to complex trait diseases that are adult onset.

DNA methylation commonly targets the cytosine at CpG sites [236]. Clusters of CpG sites, termed as CpG islands, have been identified near the transcriptional start sites (TSS) of approximately $70 \%$ of annotated genes [237]. Methylation of TSS CpG islands is correlated with transcriptional silencing [238]. Based on this observation of CpG methylation near the gene promoter region and suppression of gene transcription, efforts have been made to find links between the methylation levels of genes involved in metabolic regulation and the occurrence of metabolic disease states. Genome-wide DNA methylation analysis has been performed for monozygotic twins with or without type 2 diabetes [239]. It was found that among the 49 known type 2 susceptibility loci identified by GWAS, 8 loci in skeletal muscle and 17 loci in subcutaneous adipose tissue showed differential methylation patterns at the gene promoter regions between affected and nonaffected monozygotic twins [239]. PGC-1 $\alpha$ was one of the differentially methylated genes, which was hypermethylated in affected twin's skeletal muscle compared to unaffected [239]. The hypermethylation of the PGC- $1 \alpha$ promoter region correlates with its reduced mRNA expression level in type 2 diabetes patients [43,44]. Reciprocally, in the skeletal muscle of formerly obese individuals whose weight was normalized by gastric bypass surgery, reduced promoter DNA methylation and increased expression of the PGC- $1 \alpha$ gene were observed [240]. Inducing hypomethylation of DNA as a therapy using inhibitors for DNA methyltransferases has been explored in the cancer field [241]. Though treatment regimen could be quite different, the same principle may be applied for the therapy of metabolic syndrome in the future.

Posttranslational modifications of histone molecules $(\mathrm{H} 2 \mathrm{~A}, \mathrm{H} 2 \mathrm{~B}, \mathrm{H} 3, \mathrm{H} 4)$ regulate accessibility and recruitment of the transcription-initiating RNA polymerase II enzyme complex by tightening or loosening the chromatin structure [242]. Specific histone modifications indicate functional domains along the genome, for example, enhancer sequence, actively transcribed gene regions, and heterochromatin; thus, identifying histone modifications for individual genes at the genome wide-level will provide a supporting data for gene expression profiling in specific tissues [243-245].

The nutritional state during the fetal stage significantly affects the metabolic state of individual's adult life, and it is likely through epigenetic regulation. Using rodent models, it has been shown that the defects in glucose metabolism seen in offspring of malnourished pregnant female rats can 
be inherited to later generations [246-249]. The molecular mechanisms of transgenerational inheritance of the metabolic phenotype are not well understood; however, epigenetic changes are the most likely culprits since they not only can significantly alter the phenotype but can also transcend generations by replicating the epigenetic modifications. Accordingly, it has been reported that malnourished female rat's offspring demonstrated reduced expression of the Glut4 gene in skeletal muscle partly because of the change in acetylation and methylation levels of $\mathrm{H} 3$ molecules at the promoter region [250]. Since maternal diet-induced obesity in rodents also causes adult-onset obesity and dysfunction in glucose metabolism in offspring [251,252], investigation of maternal obesity-induced epigenetic landscape in insulinresponsive peripheral tissues in the offspring would uncover the critical molecular changes responsible for their adultonset metabolic syndrome.

Genome-wide analysis of histone modifications for metabolic syndrome is not yet available; however, targeted inactivation of histone modification enzymes in mice has indicated a link between histone modifications and manifestation of metabolic syndrome. The JHDM2A gene (jumonji C-domain-containing histone demethylase $2 \mathrm{~A}$ ) removes histone H3 lysine 9 (H3 K9) methylation, an epigenetic marker for transcriptional silencing [253]. Knockout mice for the JHDM2A gene develop adult onset obesity (not due to food intake), hyperlipidemia, and defects in glucose metabolism $[254,255]$. In skeletal muscle of these mice, genes involved in lipid metabolism were significantly downregulated [255]. It has also been reported that mutations in the H3 K4 methyltransferase gene, MLL2, which marks transcriptionally active promoter regions during development [256], result in metabolic syndrome in mice. Mice heterozygous for a null mutation of the MLL2 gene develop hyperglycemia, hyperinsulinaemia, and insulin resistance [257]. Taken together, histone modifications during development have a decisive impact on the adult metabolic phenotype and likely hold many answers for the hereditary nature of metabolic syndrome.

\section{Concluding Remarks}

Skeletal muscle is responsible for the majority of insulininduced glucose uptake. Reduction in oxidative metabolic capacity in muscle is significantly associated with obesity and type 2 diabetes. Because of its adaptability and accessibility, skeletal muscle remodeling could be a viable therapeutic approach for metabolic syndrome. Recent advance in GWAS and animal model studies for metabolic syndrome present multiple genes and signaling pathways for use as therapeutic targets. As more detailed molecular mechanisms, especially epigenetic regulation, are revealed, manipulating physiological properties of skeletal muscle holds a promise for treatment of obesity-induced clinical conditions.

\section{Conflict of Interests}

The author declares that there is no conflict of interests regarding the publication of this paper.

\section{Acknowledgments}

This work was supported by research grants from NIH (R01 AR055209) and the University of California, Davis, School of Medicine (New Research Initiatives and Collaborative Interdisciplinary Research Grant).

\section{References}

[1] D. E. King, E. Matheson, S. Chirina, A. Shankar, and J. BromanFulks, "The status of baby boomers' health in the United States: the healthiest generation?" JAMA Internal Medicine, vol. 173, no. 5, pp. 385-386, 2013.

[2] S. M. Grundy, H. B. Brewer Jr., J. I. Cleeman, S. C. Smith Jr., and C. Lenfant, "Definition of metabolic syndrome report of the National Heart, Lung, and Blood Institute/American Heart Association Conference on scientific issues related to definition," Circulation, vol. 109, no. 3, pp. 433-438, 2004.

[3] K. Alberti and P. Zimmet, "Definition, diagnosis and classification of diabetes mellitus provisional report of a WHO consultation," Diabetic Medicine, vol. 15, no. 7, pp. 539-553, 1998.

[4] E. Kassi, P. Pervanidou, G. Kaltsas, and G. Chrousos, "Metabolic syndrome: definitions and controversies," BMC Medicine, vol. 9, article 48, 2011.

[5] M. Espeland, X. Pi-Sunyer, G. Blackburn et al., "Reduction in weight and cardiovascular disease risk factors in individuals with type 2 diabetes one-year results of the look AHEAD trial," Diabetes Care, vol. 30, no. 6, pp. 1374-1383, 2007.

[6] R. R. Wing, P. Bolin, F. L. Brancati et al., "Cardiovascular effects of intensive lifestyle intervention in type 2 diabetes," The New England Journal of Medicine, vol. 369, no. 2, pp. 145-154, 2013.

[7] Ameircan Diabetes Association, "Standards of medical care in diabetes-2014," Diabetes Care, vol. 37, supplement 1, pp. S14S80, 2014.

[8] H. N. Ginsberg, "Insulin resistance and cardiovascular disease," Journal of Clinical Investigation, vol. 106, no. 4, pp. 453-458, 2000.

[9] A. D. Baron, G. Brechtel, P. Wallace, and S. V. Edelman, "Rates and tissue sites of non-insulin- and insulin-mediated glucose uptake in humans," American Journal of Physiology. Endocrinology and Metabolism, vol. 255, no. 6, pp. E769-E774, 1988.

[10] D. Thiebaud, E. Jacot, R. A. DeFronzo, E. Maeder, E. Jequier, and J. P. Felber, "The effect of graded doses of insulin on total glucose uptake, glucose oxidation, and glucose storage in man," Diabetes, vol. 31, no. 11, pp. 957-963, 1982.

[11] K. F. Petersen, S. Dufour, D. B. Savage et al., "The role of skeletal muscle insulin resistance in the pathogenesis of the metabolic syndrome," Proceedings of the National Academy of Sciences of the United States of America, vol. 104, no. 31, pp. 12587-12594, 2007.

[12] S. Schiaffino, "Fibre types in skeletal muscle: a personal account," Acta Physiologica, vol. 199, no. 4, pp. 451-463, 2010.

[13] J. R. Zierath and J. A. Hawley, "Skeletal muscle fiber type: influence on contractile and metabolic properties," PLoS Biology, vol. 2, no. 10, Article ID e348, 2004.

[14] L. Ranvier, "Propriétés etstructures différentes des muscles rouges et des muscles blancs chez les lapins et chez les raies," CR Acad Sci Paris, vol. 77, pp. 1030-1034, 1873.

[15] D. M. Needam, "Red ans white muscle," Physiological Reviews, vol. 6, no. 1, pp. 1-27, 1926. 
[16] M. Bárány, "ATPase activity of myosin correlated with speed of muscle shortening," The Journal of General Physiology, vol. 50, no. 6, pp. 197-218, 1967.

[17] S. Schiaffino, V. Hanzlíková, and S. Pierobon, "Relations between structure and function in rat skeletal muscle fibers.," Journal of Cell Biology, vol. 47, no. 1, pp. 107-119, 1970.

[18] G. J. M. Stienen, J. L. Kiers, R. Bottinelli, and C. Reggiani, "Myofibrillar ATPase activity in skinned human skeletal muscle fibres: fibre type and temperature dependence," Journal of Physiology, vol. 493, part 2, pp. 299-307, 1996.

[19] L. Larsson and R. L. Moss, "Maximum velocity of shortening in relation to myosin isoform composition in single fibres from human skeletal muscles," Journal of Physiology, vol. 472, pp. 595-614, 1993.

[20] R. S. Staron, “Correlation between myofibrillar ATPase activity and myosin heavy chain composition in single human muscle fibers," Histochemistry, vol. 96, no. 1, pp. 21-24, 1991.

[21] J. B. Peter, R. J. Barnard, V. R. Edgerton, C. A. Gillespie, and K. E. Stempel, "Metabolic profiles of three fiber types of skeletal muscle in guinea pigs and rabbits," Biochemistry, vol. 11, no. 14, pp. 2627-2633, 1972.

[22] B. C. Harrison, D. L. Allen, B. Girten et al., "Skeletal muscle adaptations to microgravity exposure in the mouse," Journal of Applied Physiology, vol. 95, no. 6, pp. 2462-2470, 2003.

[23] D. Sandonà, J. Desaphy, G. M. Camerino et al., "Adaptation of mouse skeletal muscle to long-term microgravity in the MDS mission," PLoS ONE, vol. 7, no. 3, Article ID e33232, 2012.

[24] S. Trappe, T. Trappe, P. Gallagher, M. Harber, B. Alkner, and P. Tesch, "Human single muscle fibre function with 84 day bedrest and resistance exercise," The Journal of Physiology, vol. 557, no. 2, pp. 501-513, 2004.

[25] D. B. Thomason and F. W. Booth, "Atrophy of the soleus muscle by hindlimb unweighting," Journal of Applied Physiology, vol. 68, no. 1, pp. 1-12, 1990.

[26] A. Bonen, M. H. Tan, and W. M. Watson-Wright, "Insulin binding and glucose uptake differences in rodent skeletal muscles," Diabetes, vol. 30, no. 8, pp. 702-704, 1981.

[27] J. R. Daugaard and E. A. Richter, "Relationship between muscle fibre composition, glucose transporter protein 4 and exercise training: possible consequences in non-insulin-dependent diabetes mellitus," Acta Physiologica Scandinavica, vol. 171, no. 3, pp. 267-276, 2001.

[28] M. Gaster, P. Poulsen, A. Handberg, H. D. Schrøder, and H. Beck-Nielsen, "Direct evidence of fiber type-dependent GLUT4 expression in human skeletal muscle," The American Journal of Physiology-Endocrinology and Metabolism, vol. 278, no. 5, pp. E910-E916, 2000.

[29] E. J. Henriksen, R. E. Bourey, K. J. Rodnick, L. Koranyi, M. A. Permutt, and J. O. Holloszy, "Glucose transporter protein content and glucose transport capacity in rat skeletal muscles," American Journal of Physiology. Endocrinology and Metabolism, vol. 259, no. 4, pp. E593-E598, 1990.

[30] J. R. Zierath, L. He, A. Gumà, E. O. Wahlström, A. Klip, and H. Wallberg-Henriksson, "Insulin action on glucose transport and plasma membrane GLUT4 content in skeletal muscle from patients with NIDDM,' Diabetologia, vol. 39, no. 10, pp. 11801189, 1996.

[31] J. He, S. Watkins, and D. E. Kelley, "Skeletal muscle lipid content and oxidative enzyme activity in relation to muscle fiber type in type 2 diabetes and obesity," Diabetes, vol. 50, no. 4, pp. 817-823, 2001.
[32] M. S. Hickey, J. O. Carey, J. L. Azevedo et al., "Skeletal muscle fiber composition is related to adiposity and in vitro glucose transport rate in humans," The American Journal of PhysiologyEndocrinology and Metabolism, vol. 268, no. 3, pp. E453-E457, 1995.

[33] S. Lillioja, A. A. Young, C. L. Culter et al., "Skeletal muscle capillary density and fiber type are possible determinants of in vivo insulin resistance in man," The Journal of Clinical Investigation, vol. 80, no. 2, pp. 415-424, 1987.

[34] C. A. Maltin, "Muscle development and obesity: is there a relationship?” Organogenesis, vol. 4, no. 3, pp. 158-169, 2008.

[35] P. Mårin, B. Andersson, M. Krotkiewski, and P. Björntorp, "Muscle fiber composition and capillary density in women and men with NIDDM," Diabetes Care, vol. 17, no. 5, pp. 382-386, 1994.

[36] M. Gaster, P. Staehr, H. Beck-Nielsen, H. D. Schrøder, and A. Handberg, "GLUT4 is reduced in slow muscle fibers of type 2 diabetic patients: is insulin resistance in type 2 diabetes a slow, type 1 fiber disease?" Diabetes, vol. 50, no. 6, pp. 1324-1329, 2001.

[37] A. Oberbach, Y. Bossenz, S. Lehmann et al., "Altered fiber distribution and fiber-specific glycolytic and oxidative enzyme activity in skeletal muscle of patients with type 2 diabetes," Diabetes Care, vol. 29, no. 4, pp. 895-900, 2006.

[38] J. A. Simoneau, S. R. Colberg, F. L. Thaete, and D. E. Kelley, "Skeletal muscle glycolitic and oxidative enzyme capacities are determinants of insulin sensitivity and muscle composition in obese women," The FASEB Journal, vol. 9, no. 2, pp. 273-278, 1995.

[39] J. A. Simoneau and D. E. Kelley, "Altered glycolytic and oxidative capacities of skeletal muscle contribute to insulin resistance in NIDDM," Journal of Applied Physiology, vol. 83, no. 1, pp. 166171, 1997.

[40] J. Simoneau, J. H. Veerkamp, L. P. Turcotte, and D. E. Kelley, "Markers of capacity to utilize fatty acids in human skeletal muscle: relation to insulin resistance and obesity and effects of weight loss," The FASEB Journal, vol. 13, no. 14, pp. 2051-2060, 1999.

[41] C. A. Stuart, M. P. McCurry, A. Marino et al., "Slow-twitch fiber proportion in skeletal muscle correlates with insulin responsiveness," The Journal of Clinical Endocrinology \& Metabolism, vol. 98, no. 5, pp. 2027-2036, 2013.

[42] C. J. Tanner, H. A. Barakat, G. Lynis Dohm et al., "Muscle fiber type is associated with obesity and weight loss," American Journal of Physiology: Endocrinology and Metabolism, vol. 282, no. 6, pp. E1191-E1196, 2002.

[43] V. K. Mootha, C. M. Lindgren, K. Eriksson et al., "PGC$1 \alpha$-responsive genes involved in oxidative phosphorylation are coordinately downregulated in human diabetes," Nature Genetics, vol. 34, no. 3, pp. 267-273, 2003.

[44] M. E. Patti, A. J. Butte, S. Crunkhorn et al., "Coordinated reduction of genes of oxidative metabolism in humans with insulin resistance and diabetes: potential role of PGC1 and NRF1," Proceedings of the National Academy of Sciences of the United States of America, vol. 100, no. 14, pp. 8466-8471, 2003.

[45] R. Sreekumar, P. Halvatsiotis, J. C. Schimke, and K. Sreekumaran Nair, "Gene expression profile in skeletal muscle of type 2 diabetes and the effect of insulin treatment," Diabetes, vol. 51, no. 6, pp. 1913-1920, 2002.

[46] B. H. Annex, C. E. Torgan, P. Lin et al., "Induction and maintenance of increased VEGF protein by chronic motor nerve stimulation in skeletal muscle," TheAmerican Journal of Physiology, vol. 274, part 2, no. 3, pp. H860-H867, 1998. 
[47] O. Hudlicka, L. Dodd, E. M. Renkin, and S. D. Gray, "Early changes in fiber profile and capillary density in long-term stimulated muscles," American Journal of Physiology. Heart and Circulatory Physiology, vol. 243, no. 4, pp. H528-H535, 1982.

[48] F. Ingjer, "Capillary supply and mitochondrial content of different skeletal muscle fiber types in untrained and endurancetrained men. A histochemical and ultrastructural study," European Journal of Applied Physiology and Occupational Physiology, vol. 40, no. 3, pp. 197-209, 1979.

[49] H. Lithell, F. Lindgarde, K. Hellsing et al., "Body weight, skeletal muscle morphology, and enzyme activities in relation to fasting serum insulin concentration and glucose tolerance in 48-yearold men," Diabetes, vol. 30, no. 1, pp. 19-25, 1981.

[50] G. Sjøgaard, "Capillary supply and cross-sectional area of slow and fast twitch muscle fibres in man," Histochemistry, vol. 76, no. 4, pp. 547-555, 1982.

[51] H. Eyre, R. Kahn, R. M. Robertson et al., "Preventing cancer, cardiovascular disease, and diabetes: a common agenda for the American Cancer Society, the American Diabetes Association, and the American Heart Association," Stroke, vol. 35, no. 8, pp. 1999-2010, 2004.

[52] T. Elgzyri, H. Parikh, Y. Zhou et al., "First-degree relatives of type 2 diabetic patients have reduced expression of genes involved in fatty acid metabolism in skeletal muscle," The Journal of Clinical Endocrinology and Metabolism, vol. 97, no. 7, pp. E1332-E1337, 2012.

[53] K. Morino, K. F. Petersen, S. Dufour et al., "Reduced mitochondrial density and increased IRS-1 serine phosphorylation in muscle of insulin-resistant offspring of type 2 diabetic parents," The Journal of Clinical Investigation, vol. 115, no. 12, pp. 35873593, 2005.

[54] K. F. Petersen, S. Dufour, D. Befroy, R. Garcia, and G. I. Shulman, "Impaired mitochondrial activity in the insulinresistant offspring of patients with type 2 diabetes," The New England Journal of Medicine, vol. 350, no. 7, pp. 664-671, 2004.

[55] J.-A. Simoneau and C. Bouchard, "Genetic determinism of fiber type proportion in human skeletal muscle," The FASEB Journal, vol. 9, no. 11, pp. 1091-1095, 1995.

[56] B. C. Martin, J. H. Warram, A. S. Krolewski, R. N. Bergman, J. S. Soeldner, and C. R. Kahn, "Role of glucose and insulin resistance in development of type 2 diabetes mellitus: results of a 25-year follow-up study," The Lancet, vol. 340, no. 8825, pp. 925-929, 1992.

[57] J. Eriksson, A. Franssila-Kallunki, A. Ekstrand et al., "Early metabolic defects in persons at increased risk for non-insulindependent diabetes mellitus," The New England Journal of Medicine, vol. 321, no. 6, pp. 337-343, 1989.

[58] S. Lillioja, D. M. Mott, M. Spraul et al., "Insulin resistance and insulin secretory dysfunction as precursors of non-insulindependent diabetes mellitus: prospective studies of Pima Indians," The New England Journal of Medicine, vol. 329, no. 27, pp. 1988-1992, 1993.

[59] A. Doria, M.-E. Patti, and C. R. Kahn, "The emerging genetic architecture of type 2 diabetes," Cell Metabolism, vol. 8, no. 3, pp. 186-200, 2008.

[60] K. Almind, C. Bjorbaek, H. Vestergaard, T. Hansen, S. Echwald, and O. Pedersen, "Aminoacid polymorphisms of insulin receptor substrate-1 in non-inslin-dependent diabetes mellitus," The Lancet, vol. 342, no. 8875, pp. 828-832, 1993.

[61] K. Almind, G. Inoue, O. Pedersen, and C. R. Kahn, "A common amino acid polymorphism in insulin receptor substrate-1 causes impaired insulin signaling. Evidence from transfection studies," The Journal of Clinical Investigation, vol. 97, no. 11, pp. 25692575, 1996.

[62] E. Morini, S. Prudente, E. Succurro et al., "IRS1 G972R polymorphism and type 2 diabetes: a paradigm for the difficult ascertainment of the contribution to disease susceptibility of "low-frequency-low-risk" variants," Diabetologia, vol. 52, no. 9, pp. 1852-1857, 2009.

[63] D. Altshuler, J. N. Hirschhorn, M. Klannemark et al., "The common PPAR $\gamma$ Prol2Ala polymorphism is associated with decreased risk of type 2 diabetes," Nature Genetics, vol. 26, no. 1, pp. 76-80, 2000.

[64] J. Rung, S. Cauchi, A. Albrechtsen et al., "Genetic variant near IRS1 is associated with type 2 diabetes, insulin resistance and hyperinsulinemia," Nature Genetics, vol. 41, no. 10, pp. 1110-1115, 2009.

[65] Y. Tang, X. Han, X. Sun et al., "Association study of a common variant near IRS1 with type 2 diabetes mellitus in Chinese Han population," Endocrine, vol. 43, no. 1, pp. 84-91, 2013.

[66] A. P. Morris, B. F. Voight, T. M. Teslovich et al., "Largescale association analysis provides insights into the genetic architecture and pathophysiology of type 2 diabetes," Nature Genetics, vol. 44, no. 9, pp. 981-990, 2012.

[67] B. F. Voight, L. J. Scott, V. Steinthorsdottir et al., "Twelve type 2 diabetes susceptibility loci identified through large-scale association analysis," Nature Genetics, vol. 42, no. 7, pp. 579-589, 2010.

[68] T. A. Manolio, F. S. Collins, N. J. Cox et al., "Finding the missing heritability of complex diseases," Nature, vol. 461, no. 7265, pp. 747-753, 2009.

[69] M. I. McCarthy, G. R. Abecasis, L. R. Cardon et al., "Genomewide association studies for complex traits: consensus, uncertainty and challenges," Nature Reviews Genetics, vol. 9, no. 5, pp. 356-369, 2008.

[70] R. J. Neuman, J. Wasson, G. Atzmon et al., "Gene-gene interactions lead to higher risk for development of type 2 diabetes in an Ashkenazi Jewish population," PLoS ONE, vol. 5, no. 3, Article ID e9903, 2010.

[71] R. Plomin, C. M. A. Haworth, and O. S. P. Davis, "Common disorders are quantitative traits," Nature Reviews Genetics, vol. 10, no. 12, pp. 872-878, 2009.

[72] X. Sim, R. T. Ong, C. Suo et al., "Transferability of type 2 diabetes implicated loci in multi-ethnic cohorts from Southeast Asia," PLoS Genetics, vol. 7, no. 4, Article ID e1001363, 2011.

[73] L. A. Hindorff, P. Sethupathy, H. A. Junkins et al., "Potential etiologic and functional implications of genome-wide association loci for human diseases and traits," Proceedings of the National Academy of Sciences of the United States of America, vol. 106, no. 23, pp. 9362-9367, 2009.

[74] J. A. Tennessen, A. W. Bigham, T. D. O'Connor et al., "Evolution and functional impact of rare coding variation from deep sequencing of human exomes," Science, vol. 337, no. 6090, pp. 64-69, 2012.

[75] K. E. Lohmueller, T. Sparsø, Q. Li et al., "Whole-exome sequencing of 2,000 Danish individuals and the role of rare coding variants in type 2 diabetes," The American Journal of Human Genetics, vol. 93, no. 6, pp. 1072-1086, 2013.

[76] J. C. Denny, M. D. Ritchie, M. A. Basford et al., "PheWAS: demonstrating the feasibility of a phenome-wide scan to discover gene-disease associations," Bioinformatics, vol. 26, no. 9, pp. 1205-1210, 2010. 
[77] J. C. Denny, L. Bastarache, M. D. Ritchie et al., "Systematic comparison of phenome-wide association study of electronic medical record data and genome-wide association study data," Nature Biotechnology, vol. 31, no. 12, pp. 1102-1111, 2013.

[78] S. J. Hebbring, "The challenges, advantages and future of phenome-wide association studies," Immunology, vol. 141, no. 2, pp. 157-165, 2014.

[79] S. A. Pendergrass, K. Brown-Gentry, S. Dudek et al., "PhenomeWide Association Study (PheWAS) for detection of pleiotropy within the Population Architecture using Genomics and Epidemiology (PAGE) network," PLoS Genetics, vol. 9, no. 1, Article ID e1003087, 2013.

[80] K. D. Baker and C. S. Thummel, "Diabetic larvae and obese flies-emerging studies of metabolism in Drosophila," Cell Metabolism, vol. 6, no. 4, pp. 257-266, 2007.

[81] S. K. Kim and E. J. Rulifson, "Conserved mechanisms of glucose sensing and regulation by Drosophila corpora cardiaca cells," Nature, vol. 431, no. 7006, pp. 316-320, 2004.

[82] S. Oldham and E. Hafen, "Insulin/IGF and target of rapamycin signaling: a TOR de force in growth control," Trends in Cell Biology, vol. 13, no. 2, pp. 79-85, 2003.

[83] R. T. Birse, J. Choi, K. Reardon et al., "High-fat-diet-induced obesity and heart dysfunction are regulated by the TOR pathway in Drosophila," Cell Metabolism, vol. 12, no. 5, pp. 533-544, 2010.

[84] J. Pendse, P. V. Ramachandran, J. Na et al., "A Drosophila functional evaluation of candidates from human genome-wide association studies of type 2 diabetes and related metabolic traits identifies tissue-specific roles for dHHEX," BMC Genomics, vol. 14, article 136, 2013.

[85] S. Fröjdö, C. Durand, L. Molin et al., "Phosphoinositide 3kinase as a novel functional target for the regulation of the insulin signaling pathway by SIRT1," Molecular and Cellular Endocrinology, vol. 335, no. 2, pp. 166-176, 2011.

[86] S. Hashmi, Y. Wang, R. S. Parhar et al., "A C. elegans model to study human metabolic regulation," Nutrition and Metabolism, vol. 10, no. 1, article 31, 2013.

[87] J. Zhang, R. Bakheet, R. S. Parhar et al., "Regulation of fat storage and reproduction by Krüppel-like transcription factor KLF3 and fat-associated genes in Caenorhabditis elegans," Journal of Molecular Biology, vol. 411, no. 3, pp. 537-553, 2011.

[88] C. Slawson, R. J. Copeland, and G. W. Hart, "O-GlcNAc signaling: a metabolic link between diabetes and cancer?" Trends in Biochemical Sciences, vol. 35, no. 10, pp. 547-555, 2010.

[89] D. M. Lehman, D. Fu, A. B. Freeman et al., "A single nucleotide polymorphism in MGEA5 encoding O-GlcNAc-selective $\mathrm{N}$ acetyl- $\beta$-D glucosaminidase is associated with type 2 diabetes im Mexican Americans," Diabetes, vol. 54, no. 4, pp. 1214-1221, 2005.

[90] M. E. Forsythe, D. C. Love, B. D. Lazarus et al., "Caenorhabditis elegans ortholog of a diabetes susceptibility locus: oga-1 (OGlcNAcase) knockout impacts O-GlcNAc cycling, metabolism, and dauer," Proceedings of the National Academy of Sciences of the United States of America, vol. 103, no. 32, pp. 11952-11957, 2006.

[91] A. Seth, D. L. Stemple, and I. Barroso, "The emerging use of zebrafish to model metabolic disease," Disease Models \& Mechanisms, vol. 6, no. 5, pp. 1080-1088, 2013.

[92] V. M. Bedell, Y. Wang, J. M. Campbell et al., "In vivo genome editing using a high-efficiency TALEN system," Nature, vol. 491, no. 7422, pp. 114-118, 2012.
[93] N. Chang, C. Sun, L. Gao et al., "Genome editing with RNAguided Cas9 nuclease in Zebrafish embryos," Cell Research, vol. 23, no. 4, pp. 465-472, 2013.

[94] A. T. Chinwalla, L. L. Cook, K. D. Delehaunty et al., "Initial sequencing and comparative analysis of the mouse genome," Nature, vol. 420, no. 6915, pp. 520-562, 2002.

[95] The ENCODE Project Consortium, "A user's guide to the encyclopedia of DNA elements (ENCODE)," PLoS Biology, vol. 9, no. 4, Article ID e1001046, 2011.

[96] M. M. Hoffman, J. Ernst, S. P. Wilder et al., "Integrative annotation of chromatin elements from ENCODE data," Nucleic Acids Research, vol. 41, no. 2, pp. 827-841, 2013.

[97] C. Dina, D. Meyre, S. Gallina et al., "Variation in FTO contributes to childhood obesity and severe adult obesity," Nature Genetics, vol. 39, no. 6, pp. 724-726, 2007.

[98] T. M. Frayling, N. J. Timpson, M. N. Weedon et al., "A common variant in the FTO gene is associated with body mass index and predisposes to childhood and adult obesity," Science, vol. 316, no. 5826, pp. 889-894, 2007.

[99] A. Scuteri, S. Sanna, W. Chen et al., "Genome-wide association scan shows genetic variants in the FTO gene are associated with obesity-related traits," PLoS Genetics, vol. 3, no. 7, Article ID e115, 2007.

[100] S. A. Al-Attar, R. L. Pollex, M. R. Ban et al., "Association between the FTO rs9939609 polymorphism and the metabolic syndrome in a non-Caucasian multi-ethnic sample," Cardiovascular Diabetology, vol. 7, article 5, 2008.

[101] R. M. Freathy, N. J. Timpson, D. A. Lawlor et al., "Common variation in the FTO gene alters diabetes-related metabolic traits to the extent expected given its effect on BMI," Diabetes, vol. 57, no. 5, pp. 1419-1426, 2008.

[102] K. A. Fawcett and I. Barroso, "The genetics of obesity: FTO leads the way," Trends in Genetics, vol. 26, no. 6, pp. 266-274, 2010.

[103] C. Church, L. Moir, F. McMurray et al., "Overexpression of Fto leads to increased food intake and results in obesity," Nature Genetics, vol. 42, no. 12, pp. 1086-1092, 2010.

[104] J. Fischer, L. Koch, C. Emmerling et al., "Inactivation of the Fto gene protects from obesity," Nature, vol. 458, no. 7240, pp. 894898, 2009.

[105] X. Gao, Y. Shin, M. Li, F. Wang, Q. Tong, and P. Zhang, “The fat mass and obesity associated gene FTO functions in the brain to regulate postnatal growth in mice," PLoS ONE, vol. 5, no. 11, Article ID e14005, 2010.

[106] L. G. Grunnet, E. Nilsson, C. Ling et al., "Regulation and function of FTO mRNA expression in human skeletal muscle and subcutaneous adipose tissue," Diabetes, vol. 58, no. 10, pp. 2402-2408, 2009.

[107] N. Klöting, D. Schleinitz, K. Ruschke et al., "Inverse relationship between obesity and FTO gene expression in visceral adipose tissue in humans," Diabetologia, vol. 51, no. 4, pp. 641-647, 2008.

[108] K. Wåhlén, E. Sjölin, and J. Hoffstedt, “The common rs9939609 gene variant of the fat mass- and obesity-associated gene FTO is related to fat cell lipolysis," Journal of Lipid Research, vol. 49, no. 3, pp. 607-611, 2008.

[109] G. Stratigopoulos, S. L. Padilla, C. A. LeDuc et al., "Regulation of Fto/Ftm gene expression in mice and humans," The American Journal of Physiology-Regulatory, Integrative and Comparative Physiology, vol. 294, no. 4, pp. R1185-R1196, 2008.

[110] S. Smemo, J. J. Tena, K. H. Kim, and et al, "Obesity-associated variants within FTO form long-range functional connections with IRX3," Nature, vol. 507, no. 7492, pp. 371-375, 2014. 
[111] D. Pette and R. S. Staron, "Myosin isoforms, muscle fiber types, and transitions," Microscopy Research and Technique, vol. 50, no. 6, pp. 500-509, 2000.

[112] J. L. Andersen, A. Weiss, C. Sandri et al., "The 2B myosin heavy chain gene is expressed in human skeletal muscle," The Journal of Physiology, vol. 539, supplement, pp. 29-30, 2000.

[113] A. Weiss, D. McDonough, B. Wertman et al., "Organization of human and mouse skeletal myosin heavy chain gene clusters is highly conserved," Proceedings of the National Academy of Sciences of the United States of America, vol. 96, no. 6, pp. 29582963, 1999.

[114] R. Granit, H. D. Henatsch, and G. Steg, "Tonic and phasic ventral horn cells differentiated by post-tetanic potentiation in cat extensors," Acta Physiologica Scandinavica, vol. 37, no. 2-3, pp. 114-126, 1956.

[115] D. Pette and G. Vrbová, "What does chronic electrical stimulation teach us about muscle plasticity?" Muscle \& Nerve, vol. 22, no. 6, pp. 666-677, 1999.

[116] R. Hennig and T. Lømo, "Firing patterns of motor units in normal rats," Nature, vol. 314, no. 6007, pp. 164-166, 1985.

[117] S. Ausoni, L. Gorza, S. Schiaffino, K. Gundersen, and T. Lomo, "Expression of myosin heavy chain isoforms in stimulated fast and slow rat muscles," The Journal of Neuroscience, vol. 10, no. 1, pp. 153-160, 1990.

[118] M. Nuhr, R. Crevenna, B. Gohlsch et al., "Functional and biochemical properties of chronically stimulated human skeletal muscle," European Journal of Applied Physiology, vol. 89, no. 2, pp. 202-208, 2003.

[119] M. J. Nuhr, D. Pette, R. Berger et al., "Beneficial effects of chronic low-frequency stimulation of thigh muscles in patients with advanced chronic heart failure," European Heart Journal, vol. 25, no. 2, pp. 136-143, 2004.

[120] M. J. Sullivan, B. D. Duscha, H. Klitgaard, W. E. Kraus, F. R. Cobb, and B. Saltin, "Altered expression of myosin heavy chain in human skeletal muscle in chronic heart failure," Medicine and Science in Sports and Exercise, vol. 29, no. 7, pp. 860-866, 1997.

[121] B. B. Lowell and G. I. Shulman, "Mitochondrial dysfunction and type 2 diabetes," Science, vol. 307, no. 5708, pp. 384-387, 2005.

[122] C. B. Klee, H. Ren, and X. Wang, "Regulation of the calmodulinstimulated protein phosphatase, calcineurin," Journal of Biological Chemistry, vol. 273, no. 22, pp. 13367-13370, 1998.

[123] E. R. Chin, E. N. Olson, J. A. Richardson et al., "A calcineurindependent transcriptional pathway controls skeletal muscle fiber type," Genes and Development, vol. 12, no. 16, pp. 24992509, 1998.

[124] F. J. Naya, B. Mercer, J. Shelton, J. A. Richardson, R. S. Williams, and E. N. Olson, "Stimulation of slow skeletal muscle fiber gene expression by calcineurin in vivo," The Journal of Biological Chemistry, vol. 275, no. 7, pp. 4545-4548, 2000.

[125] A. L. Serrano, M. Murgia, G. Pallafacchina et al., "Calcineurin controls nerve activity-dependent specification of slow skeletal muscle fibers but not muscle growth," Proceedings of the National Academy of Sciences of the United States of America, vol. 98, no. 23, pp. 13108-13113, 2001.

[126] E. Calabria, S. Ciciliot, I. Moretti et al., "NFAT isoforms control activity-dependent muscle fiber type specification," Proceedings of the National Academy of Sciences of the United States of America, vol. 106, no. 32, pp. 13335-13340, 2009.

[127] P. G. Hogan, L. Chen, J. Nardone, and A. Rao, “Transcriptional regulation by calcium, calcineurin, and NFAT," Genes and Development, vol. 17, no. 18, pp. 2205-2232, 2003.
[128] J. D. Meissner, P. K. Umeda, K. Chang, G. Gros, and R. J. Scheibe, "Activation of the $\beta$ myosin heavy chain promoter by MEF-2D, MyoD, p300, and the calcineurin/NFATc1 pathway," Journal of Cellular Physiology, vol. 211, no. 1, pp. 138-148, 2007.

[129] Z. A. Rana, K. Gundersen, A. Buonanno, and D. Vullhorst, "Imaging transcription in vivo: distinct regulatory effects of fast and slow activity patterns on promoter elements from vertebrate troponin I isoform genes," The Journal of Physiology, vol. 562, part 3, pp. 815-828, 2005.

[130] Z. A. Rana, K. Gundersen, and A. Buonanno, "Activitydependent repression of muscle genes by NFAT," Proceedings of the National Academy of Sciences of the United States of America, vol. 105, no. 15, pp. 5921-5926, 2008.

[131] J. Tothova, B. Blaauw, G. Pallafacchina et al., "NFATc1 nucleocytoplasmic shuttling is controlled by nerve activity in skeletal muscle," Journal of Cell Science, vol. 119, no. 8, pp. 1604-1611, 2006.

[132] J. A. Drenning, V. A. Lira, C. G. Simmons, Q. A. Soltow, J. E. Sellman, and D. S. Criswell, "Nitric oxide facilitates NFATdependent transcription in mouse myotubes," The American Journal of Physiology-Cell Physiology, vol. 294, no. 4, pp. C1088-C1095, 2008.

[133] J. S. Stamler and G. Meissner, "Physiology of nitric oxide in skeletal muscle," Physiological Reviews, vol. 81, no. 1, pp. 209237, 2001.

[134] P. J. Reiser, W. O. Kline, and P. L. Vaghy, "Induction of neuronal type nitric oxide synthase in skeletal muscle by chronic electrical stimulation in vivo," Journal of Applied Physiology, vol. 82, no. 4, pp. 1250-1255, 1997.

[135] K. J. B. Martins, M. St-Louis, G. K. Murdoch et al., "Nitric oxide synthase inhibition prevents activity-induced calcineurinNFATc1 signalling and fast-to-slow skeletal muscle fibre type conversions," Journal of Physiology, vol. 590, no. 6, pp. 1427$1442,2012$.

[136] K. Punkt, M. Fritzsche, C. Stockmar et al., "Nitric oxide synthase in human skeletal muscles related to defined fibre types," Histochemistry and Cell Biology, vol. 125, no. 5, pp. 567-573, 2006.

[137] S. R. Kashyap, L. J. Roman, J. Lamont et al., "Insulin resistance is associated with impaired nitric oxide synthase activity in skeletal muscle of type 2 diabetic subjects," Journal of Clinical Endocrinology and Metabolism, vol. 90, no. 2, pp. 1100-1105, 2005.

[138] P. de Koninck and H. Schulman, "Sensitivity of CaM kinase II to the frequency of $\mathrm{Ca}^{2+}$ oscillations," Science, vol. 279, no. 5348, pp. 227-230, 1998.

[139] F. Eshete and R. D. Fields, "Spike frequency decoding and autonomous activation of $\mathrm{Ca}^{2+}$-calmodulin-dependent protein kinase II in dorsal root ganglion neurons," Journal of Neuroscience, vol. 21, no. 17, pp. 6694-6705, 2001.

[140] M. Pelosi and A. Donella-Deana, "Localization, purification, and characterization of the rabbit sarcoplasmic reticulum associated calmodulin-dependent protein kinase," Biochemistry, vol. 65 , no. 2, pp. 259-268, 2000.

[141] A. J. Rose and M. Hargreaves, "Exercise increases $\mathrm{Ca}^{2+}$ calmodulin-dependent protein kinase II activity in human skeletal muscle," The Journal of Physiology, vol. 553, no. 1, pp. 303-309, 2003.

[142] A. J. Rose, B. Kiens, and E. A. Richter, " $\mathrm{Ca}^{2+}$-calmodulindependent protein kinase expression and signalling in skeletal muscle during exercise," Journal of Physiology, vol. 574, no. 3, pp. 889-903, 2006. 
[143] H. Wu, F. J. Naya, T. A. McKinsey et al., "MEF2 responds to multiple calcium-regulated signals in the control of skeletal muscle fiber type," EMBO Journal, vol. 19, no. 9, pp. 1963-1973, 2000.

[144] H. Wu, B. Rothermel, S. Kanatous et al., "Activation of MEF2 by muscle activity is mediated through a calcineurin-dependent pathway," EMBO Journal, vol. 20, no. 22, pp. 6414-6423, 2001.

[145] U. Dressel, P. J. Bailey, S. C. Wang, M. Downes, R. M. Evans, and G. E. O. Muscat, "A Dynamic role for HDAC7 in MEF2mediated muscle differentiation," The Journal of Biological Chemistry, vol. 276, no. 20, pp. 17007-17013, 2001.

[146] C. Lemercier, A. Verdel, B. Galloo, S. Curtet, M. Brocard, and S. Khochbin, "mHDA1/HDAC5 histone deacetylase interacts with and represses MEF2A transcriptional activity," The Journal of Biological Chemistry, vol. 275, no. 20, pp. 15594-15599, 2000.

[147] E. A. Miska, C. Karlsson, E. Langley, S. J. Nielsen, J. Pines, and T. Kouzarides, "HDAC4 deacetylase associates with and represses the MEF2 transcription factor," EMBO Journal, vol. 18, no. 18, pp. 5099-5107, 1999.

[148] A. H. Wang, N. R. Bertos, M. Vezmar et al., "HDAC4, a human histone deacetylase related to yeast HDAl, is a transcriptional corepressor," Molecular and Cellular Biology, vol. 19, no. 11, pp. 7816-7827, 1999.

[149] J. Lu, T. A. McKinsey, C. Zhang, and E. N. Olson, "Regulation of skeletal myogenesis by association of the MEF2 transcription factor with class II histone deacetylases," Molecular Cell, vol. 6, no. 2, pp. 233-244, 2000.

[150] T. A. McKinsey, C.-L. Zhang, J. Lu, and E. N. Olson, "Signaldependent nuclear export of a histone deacetylase regulates muscle differentiation," Nature, vol. 408, no. 6808, pp. 106-111, 2000.

[151] Y. Liu, W. R. Randall, and M. F. Schneider, "Activity-dependent and -independent nuclear fluxes of HDAC4 mediated by different kinases in adult skeletal muscle," Journal of Cell Biology, vol. 168, no. 6, pp. 887-897, 2005.

[152] C. R. Bruce, M. J. Anderson, A. L. Carey et al., "Muscle oxidative capacity is a better predictor of insulin sensitivity than lipid status," Journal of Clinical Endocrinology and Metabolism, vol. 88, no. 11, pp. 5444-5451, 2003.

[153] M. P. Czubryt, J. McAnally, G. I. Fishman, and E. N. Olson, "Regulation of peroxisome proliferator-activated receptor $\gamma$ coactivator $1 \alpha$ (PGC- $1 \alpha)$ and mitochondrial function by MEF 2 and HDAC5," Proceedings of the National Academy of Sciences of the United States of America, vol. 100, no. 4, pp. 1711-1716, 2003.

[154] J. Lin, H. Wu, P. T. Tarr et al., "Transcriptional co-activator PGC- $1 \alpha$ drives the formation of slow-twitch muscle fibres," Nature, vol. 418, no. 6899, pp. 797-801, 2002.

[155] R. B. Vega, J. M. Huss, and D. P. Kelly, "The coactivator PGC1 cooperates with peroxisome proliferator-activated receptor $\alpha$ in transcriptional control of nuclear genes encoding mitochondrial fatty acid oxidation enzymes," Molecular and Cellular Biology, vol. 20, no. 5, pp. 1868-1876, 2000.

[156] Z. Wu, P. Puigserver, U. Andersson et al., "Mechanisms controlling mitochondrial biogenesis and respiration through the thermogenic coactivator PGC-1," Cell, vol. 98, no. 1, pp. 115-124, 1999.

[157] K. Baar, A. R. Wende, T. E. Jones et al., "Adaptations of skeletal muscle to exercise: rapid increase in the transcriptional coactivator PGC-1," The FASEB Journal, vol. 16, no. 14, pp. 18791886, 2002.

[158] H. Pilegaard, B. Saltin, and D. P. Neufer, "Exercise induces transient transcriptional activation of the PGC- $1 \alpha$ gene in human skeletal muscle," Journal of Physiology, vol. 546, no. 3, pp. 851-858, 2003.

[159] E. B. Taylor, J. D. Lamb, R. W. Hurst et al., "Endurance training increases skeletal muscle LKB1 and PGC-1 $\alpha$ protein abundance: effects of time and intensity," American Journal of Physiology. Endocrinology and Metabolism, vol. 289, no. 6, pp. E960-E968, 2005.

[160] T. Akimoto, S. C. Pohnert, P. Li et al., "Exercise stimulates Pgc$1 \alpha$ transcription in skeletal muscle through activation of the p38 MAPK pathway," Journal of Biological Chemistry, vol. 280, no. 20, pp. 19587-19593, 2005.

[161] D. C. Wright, P. C. Geiger, D. Han, T. E. Jones, and J. O. Holloszy, "Calcium induces increases in peroxisome proliferatoractivated receptor $\gamma$ coactivator- $1 \alpha$ and mitochondrial biogenesis by a pathway leading to 38 mitogen-activated protein kinase activation," The Journal of Biological Chemistry, vol. 282, no. 26, pp. 18793-18799, 2007.

[162] F. Lluís, E. Perdiguero, A. R. Nebreda, and P. Muñoz-Cánoves, "Regulation of skeletal muscle gene expression by p38 MAP kinases," Trends in Cell Biology, vol. 16, no. 1, pp. 36-44, 2006.

[163] P. Puigserver, J. Rhee, J. Lin et al., "Cytokine stimulation of energy expenditure through p38 MAP kinase activation of PPAR $\gamma$ coactivator-1," Molecular Cell, vol. 8, no. 5, pp. 971-982, 2001.

[164] W. Niu, C. Huang, Z. Nawaz et al., "Maturation of the regulation of GLUT4 activity by p38 MAPK during L6 cell myogenesis," Journal of Biological Chemistry, vol. 278, no. 20, pp. 17953-17962, 2003.

[165] T. Geng, P. Li, M. Okutsu et al., "PGC- $1 \alpha$ plays a functional role in exercise-induced mitochondrial biogenesis and angiogenesis but not fiber-type transformation in mouse skeletal muscle," The American Journal of Physiology-Cell Physiology, vol. 298, no. 3, pp. C572-C579, 2010.

[166] A. R. Pogozelski, T. Geng, P. Li et al., "p38 $\gamma$ mitogen-activated protein kinase is a key regulator in skeletal muscle metabolic adaptation in mice," PLoS ONE, vol. 4, no. 11, Article ID e7934, 2009.

[167] S. Crunkhorn, F. Dearie, C. Mantzoros et al., "Peroxisome proliferator activator receptor $\gamma$ coactivator-1 expression is reduced in obesity: potential pathogenic role of saturated fatty acids and p38 mitogen-activated protein kinase activation," The Journal of Biological Chemistry, vol. 282, no. 21, pp. 15439-15450, 2007.

[168] A. Sriwijitkamol, J. L. Ivy, C. Christ-Roberts, R. A. DeFronzo, L. J. Mandarino, and N. Musi, "LKB1-AMPK signaling in muscle from obese insulin-resistant Zucker rats and effects of training," American Journal of Physiology-Endocrinology and Metabolism, vol. 290, no. 5, pp. E925-E932, 2006.

[169] C. R. Benton, J. G. Nickerson, J. Lally et al., "Modest PGC$1 \alpha$ overexpression in muscle in vivo is sufficient to increase insulin sensitivity and palmitate oxidation in subsarcolemmal, not intermyofibrillar, mitochondria," Journal of Biological Chemistry, vol. 283, no. 7, pp. 4228-4240, 2008.

[170] D. G. Hardie, F. A. Ross, and S. A. Hawley, "AMPK: a nutrient and energy sensor that maintains energy homeostasis," Nature Reviews Molecular Cell Biology, vol. 13, no. 4, pp. 251-262, 2012.

[171] S. Jäer, C. Handschin, J. St-Pierre, and B. M. Spiegelman, "AMPactivated protein kinase (AMPK) action in skeletal muscle via direct phosphorylation of PGC-1 $\alpha$," Proceedings of the National Academy of Sciences of the United States of America, vol. 104, no. 29, pp. 12017-12022, 2007. 
[172] Z. Gerhart-Hines, J. T. Rodgers, O. Bare et al., "Metabolic control of muscle mitochondrial function and fatty acid oxidation through SIRT1/PGC-1 $\alpha$, EMBO Journal, vol. 26, no. 7, pp. 19131923, 2007.

[173] S. Nemoto, M. M. Fergusson, and T. Finkel, "SIRT1 functionally interacts with the metabolic regulator and transcriptional coactivator PGC-1 $\alpha$," The Journal of Biological Chemistry, vol. 280, no. 16, pp. 16456-16460, 2005.

[174] C. Cantó, Z. Gerhart-Hines, J. N. Feige et al., "AMPK regulates energy expenditure by modulating NAD+ metabolism and SIRT1 activity," Nature, vol. 458, no. 7241, pp. 1056-1060, 2009.

[175] K. Sakamoto, A. McCarthy, D. Smith et al., "Deficiency of LKB1 in skeletal muscle prevents AMPK activation and glucose uptake during contraction," EMBO Journal, vol. 24, no. 10, pp. 1810-1820, 2005.

[176] M. Lagouge, C. Argmann, Z. Gerhart-Hines et al., "Resveratrol improves mitochondrial function and protects against metabolic disease by activating SIRT1 and PGC-1 $\alpha$," Cell, vol. 127, no. 6, pp. 1109-1122, 2006.

[177] V. A. Narkar, M. Downes, R. T. Yu et al., "AMPK and PPAR $\delta$ agonists are exercise mimetics," Cell, vol. 134, no. 3, pp. 405-415, 2008.

[178] K. Svensson and C. Handschin, "Modulation of PGC-1alpha activity as a treatment for metabolic and muscle-related diseases," Drug Discovery Today, vol. 19, no. 7, pp. 1024-1029, 2014.

[179] C. Bouchard, J. A. Simoneau, G. Lortie, M. R. Boulay, M. Marcotte, and M. C. Thibault, "Genetic effects in human skeletal muscle fiber type distribution and enzyme activities," Canadian Journal of Physiology and Pharmacology, vol. 64, no. 9, pp. 12451251, 1986.

[180] P. V. Komi, J. H. T. Viitasalo, M. Havu, A. Thorstensson, B. Sjödin, and J. Karlsson, "Skeletal muscle fibres and muscle enzyme activities in monozygous and dizygous twins of both sexes," Acta Physiologica Scandinavica, vol. 100, no. 4, pp. 385392, 1977.

[181] K. Condon, L. Silberstein, H. M. Blau, and W. J. Thompson, "Differentiation of fiber types in aneural musculature of the prenatal rat hindlimb," Developmental Biology, vol. 138, no. 2, pp. 275-295, 1990.

[182] P. W. Sheard and M. J. Duxson, "Composition of newly forming motor units in prenatal rat intercostal muscle," Developmental Dynamics, vol. 205, no. 2, pp. 196-212, 1996.

[183] M. Oh, I. I. Rybkin, V. Copeland et al., "Calcineurin is necessary for the maintenance but not embryonic development of slow muscle fibers," Molecular and Cellular Biology, vol. 25, no. 15, pp. 6629-6638, 2005.

[184] S. Biressi, M. Molinaro, and G. Cossu, "Cellular heterogeneity during vertebrate skeletal muscle development," Developmental Biology, vol. 308, no. 2, pp. 281-293, 2007.

[185] F. E. Stockdale, "Myogenic cell lineages," Developmental Biology, vol. 154, no. 2, pp. 284-298, 1992.

[186] M. Narusawa, R. B. Fitzsimons, S. Izumo, B. Nadal-Ginard, N. A. Rubinstein, and A. M. Kelly, "Slow myosin in developing rat skeletal muscle," Journal of Cell Biology, vol. 104, no. 3, pp. 447459, 1987.

[187] L. G. Robson and S. M. Hughes, "Local signals in the chick limb bud can override myoblast lineage commitment: induction of slow myosin heavy chain in fast myoblasts," Mechanisms of Development, vol. 85, no. 1-2, pp. 59-71, 1999.

[188] A. S. Cachaço, S. M. Chuva de Sousa Lopes, I. Kuikman et al., "Knock-in of integrin $\beta 1 \mathrm{D}$ affects primary but not secondary myogenesis in mice," Development, vol. 130, no. 8, pp. 1659-1671, 2003.

[189] P. M. Wigmore and G. F. Dunglison, "The generation of fiber diversity during myogenesis," International Journal of Developmental Biology, vol. 42, no. 2, pp. 117-125, 1998.

[190] J. P. Barbet, L.-E. Thornell, and G. S. Butler-Browne, "Immunocytochemical characterisation of two generations of fibers during the development of the human quadriceps muscle," Mechanisms of Development, vol. 35, no. 1, pp. 3-11, 1991.

[191] A. Aziz, S. Sebastian, and J. Dilworth, "The origin and fate of muscle satellite cells," Stem Cell Reviews and Reports, vol. 8, no. 2, pp. 609-622, 2012.

[192] J. D. Rosenblatt, D. J. Parry, and T. A. Partridge, "Phenotype of adult mouse muscle myoblasts reflects their fiber type of origin," Differentiation, vol. 60, no. 1, pp. 39-45, 1996.

[193] J. M. Kalhovde, R. Jerkovic, I. Sefland et al., "“Fast” and "slow" muscle fibres in hindlimb muscles of adult rats regenerate from intrinsically different satellite cells," The Journal of Physiology, vol. 562, no. 3, pp. 847-857, 2005.

[194] N. Hagiwara, M. Yeh, and A. Liu, "Sox6 is required for normal fiber type differentiation of fetal skeletal muscle in mice," Developmental Dynamics, vol. 236, no. 8, pp. 2062-2076, 2007.

[195] N. Hagiwara, "Sox6, jack of all trades: a versatile regulatory protein in vertebrate development," Developmental Dynamics, vol. 240, no. 6, pp. 1311-1321, 2011.

[196] C. An, Y. Dong, and N. Hagiwara, "Genome-wide mapping of Sox6 binding sites in skeletal muscle reveals both direct and indirect regulation of muscle terminal differentiation by Sox6," BMC Developmental Biology, vol. 11, article 59, 2011.

[197] D. Quiat, K. A. Voelker, J. Pei et al., "Concerted regulation of myofiber-specific gene expression and muscle performance by the transcriptional repressor Sox6," Proceedings of the National Academy of Sciences of the United States of America, vol. 108, no. 25, pp. 10196-10201, 2011.

[198] V. A. Narkar, W. Fan, M. Downes et al., "Exercise and PGC-1 $\alpha$ independent synchronization of type i muscle metabolism and vasculature by ERRy," Cell Metabolism, vol. 13, no. 3, pp. 283293, 2011.

[199] S. M. Rangwala, X. Wang, J. A. Calvo et al., "Estrogen-related receptor $\gamma$ is a key regulator of muscle mitochondrial activity and oxidative capacity," The Journal of Biological Chemistry, vol. 285, no. 29, pp. 22619-22629, 2010.

[200] J. J. McCarthy, K. A. Esser, C. A. Peterson, and E. E. DupontVersteegden, "Evidence of MyomiR network regulation of $\beta$ myosin heavy chain gene expression during skeletal muscle atrophy," Physiological Genomics, vol. 39, no. 3, pp. 219-226, 2009.

[201] E. van Rooij, D. Quiat, B. A. Johnson et al., "A family of microRNAs encoded by myosin genes governs myosin expression and muscle performance," Developmental Cell, vol. 17, no. 5, pp. 662673, 2009.

[202] Z. Gan, J. Rumsey, B. C. Hazen et al., "Nuclear receptor/microRNA circuitry links muscle fiber type to energy metabolism," The Journal of Clinical Investigation, vol. 123, no. 6, pp. 2564-2575, 2013.

[203] R. J. Delahanty, A. Beeghly-Fadiel, Y. Xiang et al., "Association of obesity-related genetic variants with endometrial cancer risk: a report from the shanghai endometrial cancer genetics study," The American Journal of Epidemiology, vol. 174, no. 10, pp. 11151126, 2011. 
[204] N. Franceschini, E. Fox, Z. Zhang et al., "Genome-wide association analysis of blood-pressure traits in African-ancestry individuals reveals common associated genes in African and non-African populations," The American Journal of Human Genetics, vol. 93, no. 3, pp. 545-554, 2013.

[205] S. K. Ganesh, V. Tragante, W. Guo et al., "Loci influencing blood pressure identified using a cardiovascular gene-centric array," Human Molecular Genetics, vol. 22, no. 8, pp. 1663-1678, 2013.

[206] T. Johnson, T. R. Gaunt, S. J. Newhouse, S. Padmanabhan, M. Tomaszewski, and M. Kumari, "Blood pressure loci identified with a gene-centric array," The American Journal of Human Genetics, vol. 89, no. 6, pp. 688-700, 2011.

[207] R. Grifone, C. Laclef, F. Spitz et al., "Sixl and Eyal expression can reprogram adult muscle from the slow-twitch phenotype into the fast-twitch phenotype," Molecular and Cellular Biology, vol. 24, no. 14, pp. 6253-6267, 2004.

[208] A. F. Richard, J. Demignon, I. Sakakibara et al., "Genesis of muscle fiber-type diversity during mouse embryogenesis relies on Sixl and Six4 gene expression," Developmental Biology, vol. 359, no. 2, pp. 303-320, 2011.

[209] J. W. Ryder, R. Bassel-Duby, E. N. Olson, and J. R. Zierath, "Skeletal muscle reprogramming by activation of calcineurin improves insulin action on metabolic pathways," Journal of Biological Chemistry, vol. 278, no. 45, pp. 44298-44304, 2003.

[210] R. C. Scarpulla, R. B. Vega, and D. P. Kelly, “Transcriptional integration of mitochondrial biogenesis," Trends in Endocrinology and Metabolism, vol. 23, no. 9, pp. 459-466, 2012.

[211] J. A. Calvo, T. G. Daniels, X. Wang et al., "Muscle-specific expression of PPAR $\gamma$ coactivator- $1 \alpha$ improves exercise performance and increases peak oxygen uptake," Journal of Applied Physiology, vol. 104, no. 5, pp. 1304-1312, 2008.

[212] C. Handschin, S. Chin, P. Li et al., "Skeletal muscle fibertype switching, exercise intolerance, and myopathy in PGC- $1 \alpha$ muscle-specific knock-out animals," The Journal of Biological Chemistry, vol. 282, no. 41, pp. 30014-30021, 2007.

[213] C. S. Choi, D. E. Befroy, R. Codella et al., "Paradoxical effects of increased expression of PGC- $1 \alpha$ on muscle mitochondrial function and insulin-stimulated muscle glucose metabolism," Proceedings of the National Academy of Sciences of the United States of America, vol. 105, no. 50, pp. 19926-19931, 2008.

[214] B. D. Hegarty, S. M. Furler, J. Ye, G. J. Cooney, and E. W. Kraegen, "The role of intramuscular lipid in insulin resistance," Acta Physiologica Scandinavica, vol. 178, no. 4, pp. 373-383, 2003.

[215] B. N. Finck, X. Han, M. Courtois et al., "A critical role for PPAR $\alpha$-mediated lipotoxicity in the pathogenesis of diabetic cardiomyopathy: modulation by dietary fat content," Proceedings of the National Academy of Sciences of the United States of America, vol. 100, no. 3, pp. 1226-1231, 2003.

[216] B. N. Finck, C. Bernal-Mizrachi, D. H. Han et al., "A potential link between muscle peroxisome proliferator- activated receptor- $\alpha$ signaling and obesity-related diabetes," Cell Metabolism, vol. 1, no. 2, pp. 133-144, 2005.

[217] S. Kleiner, V. Nguyen-Tran, O. Baré, X. Huang, B. Spiegelman, and $\mathrm{Z}$. Wu, "PPAR $\delta$ agonism activates fatty acid oxidation via PGC- $1 \alpha$ but does not increase mitochondrial gene expression and function," The Journal of Biological Chemistry, vol. 284, no. 28, pp. 18624-18633, 2009.

[218] T. Tanaka, J. Yamamoto, S. Iwasaki et al., "Activation of peroxisome proliferator-activated receptor $\delta$ induces fatty acid $\beta$-oxidation in skeletal muscle and attenuates metabolic syndrome," Proceedings of the National Academy of Sciences of the United States of America, vol. 100, no. 26, pp. 15924-15929, 2003.
[219] Y. X. Wang, C. L. Zhang, R. T. Yu et al., "Regulation of muscle fiber type and running endurance by PPAR $\delta$," PLoS Biology, vol. 2, no. 10, article e294, 2004.

[220] D. G. Hardie, "AMPK: a target for drugs and natural products with effects on both diabetes and cancer," Diabetes, vol. 62, no. 7, pp. 2164-2172, 2013.

[221] R. J. Shaw, K. A. Lamia, D. Vasquez et al., "Medicine: the kinase LKB1 mediates glucose homeostasis in liver and therapeutic effects of metformin," Science, vol. 310, no. 5754, pp. 1642-1646, 2005.

[222] M. Zang, A. Zuccollo, X. Hou et al., "AMP-activated protein kinase is required for the lipid-lowering effect of metformin in insulin-resistant human HepG2 cells," Journal of Biological Chemistry, vol. 279, no. 46, pp. 47898-47905, 2004.

[223] L. Lantier, J. Fentz, R. Mounier, and et al, "AMPK controls exercise endurance, mitochondrial oxidative capacity and skeletal muscle integrity," The FASEB Journal, pp. 3211-3224, Jul 2014.

[224] H. M. O’Neill, S. J. Maarbjerg, J. D. Crane et al., "AMP-activated protein kinase (AMPK) $\beta 1 \beta 2$ muscle null mice reveal an essential role for AMPK in maintaining mitochondrial content and glucose uptake during exercise," Proceedings of the National Academy of Sciences of the United States of America, vol. 108, no. 38, pp. 16092-16097, 2011.

[225] B. R. Barnes, S. Marklund, T. L. Steiler et al., "The 5'-AMPactivated protein kinase $\gamma 3$ isoform has a key role in carbohydrate and lipid metabolism in glycolytic skeletal muscle," Journal of Biological Chemistry, vol. 279, no. 37, pp. 38441-38447, 2004.

[226] M. Mahlapuu, C. Johansson, K. Lindgren et al., "Expression profiling of the $\gamma$-subunit isoforms of AMP-activated protein kinase suggests a major role for $\gamma 3$ in white skeletal muscle," The American Journal of Physiology: Endocrinology and Metabolism, vol. 286, no. 2, pp. E194-E200, 2004.

[227] B. R. Barnes, C. L. Yun, T. L. Steiler et al., "Changes in exerciseinduced gene expression in $5^{\prime}$-AMP-activated protein kinase $\gamma 3$-null and $\gamma 3$ R225Q transgenic mice," Diabetes, vol. 54, no. 12, pp. 3484-3489, 2005.

[228] B. B. Zhang, G. Zhou, and C. Li, "AMPK: an emerging drug target for diabetes and the metabolic syndrome," Cell Metabolism, vol. 9, no. 5, pp. 407-416, 2009.

[229] E. S. Buhl, N. Jessen, R. Pold et al., "Long-term AICAR administration reduces metabolic disturbances and lowers blood pressure in rats displaying features of the insulin resistance syndrome," Diabetes, vol. 51, no. 7, pp. 2199-2206, 2002.

[230] X. M. Song, M. Fiedler, D. Galuska et al., "5-Aminoimidazole4-carboxamide ribonucleoside treatment improves glucose homeostasis in insulin-resistant diabetic (ob/ob) mice," Diabetologia, vol. 45, no. 1, pp. 56-65, 2002.

[231] Z. Yang, X. Wang, Y. He et al., "The full capacity of AICAR to reduce obesity-induced inflammation and insulin resistance requires Myeloid SIRT1," PLoS ONE, vol. 7, no. 11, Article ID e49935, 2012.

[232] Y. Izumiya, T. Hopkins, C. Morris et al., "Fast/glycolytic muscle fiber growth reduces fat mass and improves metabolic parameters in obese mice," Cell Metabolism, vol. 7, no. 2, pp. 159-172, 2008.

[233] R. Feil and M. F. Fraga, "Epigenetics and the environment: emerging patterns and implications," Nature Reviews Genetics, vol. 13, no. 2, pp. 97-109, 2012.

[234] H. T. Bjornsson, M. Daniele Fallin, and A. P. Feinberg, "An integrated epigenetic and genetic approach to common human disease," Trends in Genetics, vol. 20, no. 8, pp. 350-358, 2004. 
[235] M. F. Fraga, E. Ballestar, M. F. Paz et al., "Epigenetic differences arise during the lifetime of monozygotic twins," Proceedings of the National Academy of Sciences of the United States of America, vol. 102, no. 30, pp. 10604-10609, 2005.

[236] A. P. Bird, "DNA methylation and the frequency of CpG in animal DNA," Nucleic Acids Research, vol. 8, no. 7, pp. 1499$1504,1980$.

[237] S. Saxonov, P. Berg, and D. L. Brutlag, "A genome-wide analysis of $\mathrm{CpG}$ dinucleotides in the human genome distinguishes two distinct classes of promoters," Proceedings of the National Academy of Sciences of the United States of America, vol. 103, no. 5, pp. 1412-1417, 2006.

[238] R. J. Klose and A. P. Bird, "Genomic DNA methylation: The mark and its mediators," Trends in Biochemical Sciences, vol. 31, no. 2, pp. 89-97, 2006.

[239] R. Ribel-Madsen, M. F. Fraga, S. Jacobsen et al., "Genome-wide analysis of DNA methylation differences in muscle and fat from monozygotic twins discordant for type 2 diabetes," PLoS ONE, vol. 7, no. 12, Article ID e51302, 2012.

[240] R. Barres, H. Kirchner, M. Rasmussen et al., "Weight loss after gastric bypass surgery in human obesity remodels promoter methylation," Cell Reports, vol. 3, no. 4, pp. 1020-1027, 2013.

[241] J. J. Issa, "DNA methylation as a therapeutic target in cancer," Clinical Cancer Research, vol. 13, no. 6, pp. 1634-1637, 2007.

[242] T. Chen and S. Y. Dent, "Chromatin modifiers and remodellers: regulators of cellular differentiation," Nature Reviews Genetics, vol. 15, no. 2, pp. 93-106, 2014.

[243] P. Asp, R. Blum, V. Vethantham et al., "Genome-wide remodeling of the epigenetic landscape during myogenic differentiation," Proceedings of the National Academy of Sciences of the United States of America, vol. 108, no. 22, pp. E149-E158, 2011.

[244] M. P. Creyghton, A. W. Cheng, G. G. Welstead et al., "Histone $\mathrm{H} 3 \mathrm{~K} 27 \mathrm{ac}$ separates active from poised enhancers and predicts developmental state," Proceedings of the National Academy of Sciences of the United States of America, vol. 107, no. 50, pp. 21931-21936, 2010.

[245] B. Lenhard, A. Sandelin, and P. Carninci, "Metazoan promoters: emerging characteristics and insights into transcriptional regulation," Nature Reviews Genetics, vol. 13, no. 4, pp. 233-245, 2012.

[246] J. F. Martin, C. S. Johnston, C. Han, and D. C. Benyshek, "Nutritional origins of insulin resistance: a rat model for diabetes- prone human populations," The Journal of Nutrition, vol. 130, no. 4, pp. 741-744, 2000.

[247] D. C. Benyshek, C. S. Johnston, and J. F. Martin, "Glucose metabolism is altered in the adequately-nourished grandoffspring ( $\mathrm{F} 3$ generation) of rats malnourished during gestation and perinatal life," Diabetologia, vol. 49, no. 5, pp. 1117-1119, 2006.

[248] M. Thamotharan, M. Garg, S. Oak et al., "Transgenerational inheritance of the insulin-resistant phenotype in embryotransferred intrauterine growth-restricted adult female rat offspring," American Journal of Physiology: Endocrinology and Metabolism, vol. 292, no. 5, pp. E1270-E1279, 2007.

[249] E. Zambrano, P. M. Martínez-Samayoa, C. J. Bautista et al., "Sex differences in transgenerational alterations of growth and metabolism in progeny (F2) of female offspring (F1) of rats fed a low protein diet during pregnancy and lactation," Journal of Physiology, vol. 566, no. 1, pp. 225-236, 2005.

[250] N. Raychaudhuri, S. Raychaudhuri, M. Thamotharan, and S. U. Devaskar, "Histone code modifications repress glucose transporter 4 expression in the intrauterine growth-restricted offspring," Journal of Biological Chemistry, vol. 283, no. 20, pp. 13611-13626, 2008.

[251] K. Hartil, P. M. Vuguin, M. Kruse et al., "Maternal substrate utilization programs the development of the metabolic syndrome in male mice exposed to high fat in utero," Pediatric Research, vol. 66, no. 4, pp. 368-373, 2009.

[252] A. Samuelsson, P. A. Matthews, M. Argenton et al., "Dietinduced obesity in female mice leads to offspring hyperphagia, adiposity, hypertension, and insulin resistance: A novel murine model of developmental programming," Hypertension, vol. 51, no. 2, pp. 383-392, 2008.

[253] M. Tachibana, M. Nozaki, N. Takeda, and Y. Shinkai, "Functional dynamics of $\mathrm{H} 3 \mathrm{~K} 9$ methylation during meiotic prophase progression," EMBO Journal, vol. 26, no. 14, pp. 3346-3359, 2007.

[254] T. Inagaki, M. Tachibana, K. Magoori et al., "Obesity and metabolic syndrome in histone demethylase JHDM2a-deficient mice," Genes to Cells, vol. 14, no. 8, pp. 991-1001, 2009.

[255] K. Tateishi, Y. Okada, E. M. Kallin, and Y. Zhang, "Role of Jhdm $2 \mathrm{a}$ in regulating metabolic gene expression and obesity resistance," Nature, vol. 458, no. 7239, pp. 757-761, 2009.

[256] S. Glaser, S. Lubitz, K. L. Loveland et al., "The histone 3 lysine 4 methyltransferase, Mll2, is only required briefly in development and spermatogenesis," Epigenetics \& Chromatin, vol. 2, no. 1, article 5, 2009.

[257] M. Goldsworthy, N. L. Absalom, D. Schröter et al., "Mutations in Mll2, an H3K4 methyltransferase, result in insulin resistance and impaired glucose tolerance in mice," PLoS ONE, vol. 8, no. 6, Article ID e61870, 2013. 

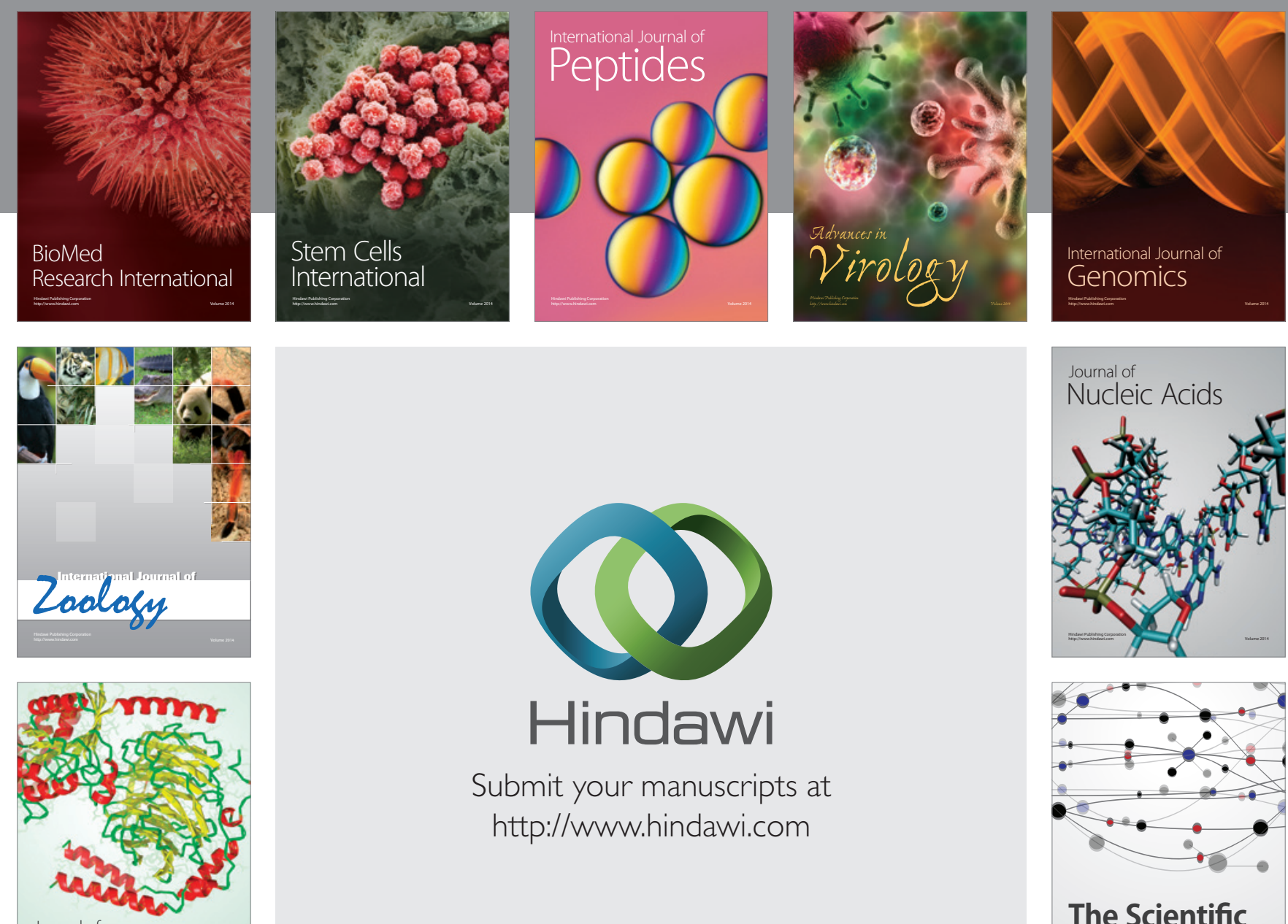

Submit your manuscripts at

http://www.hindawi.com

Journal of
Signal Transduction
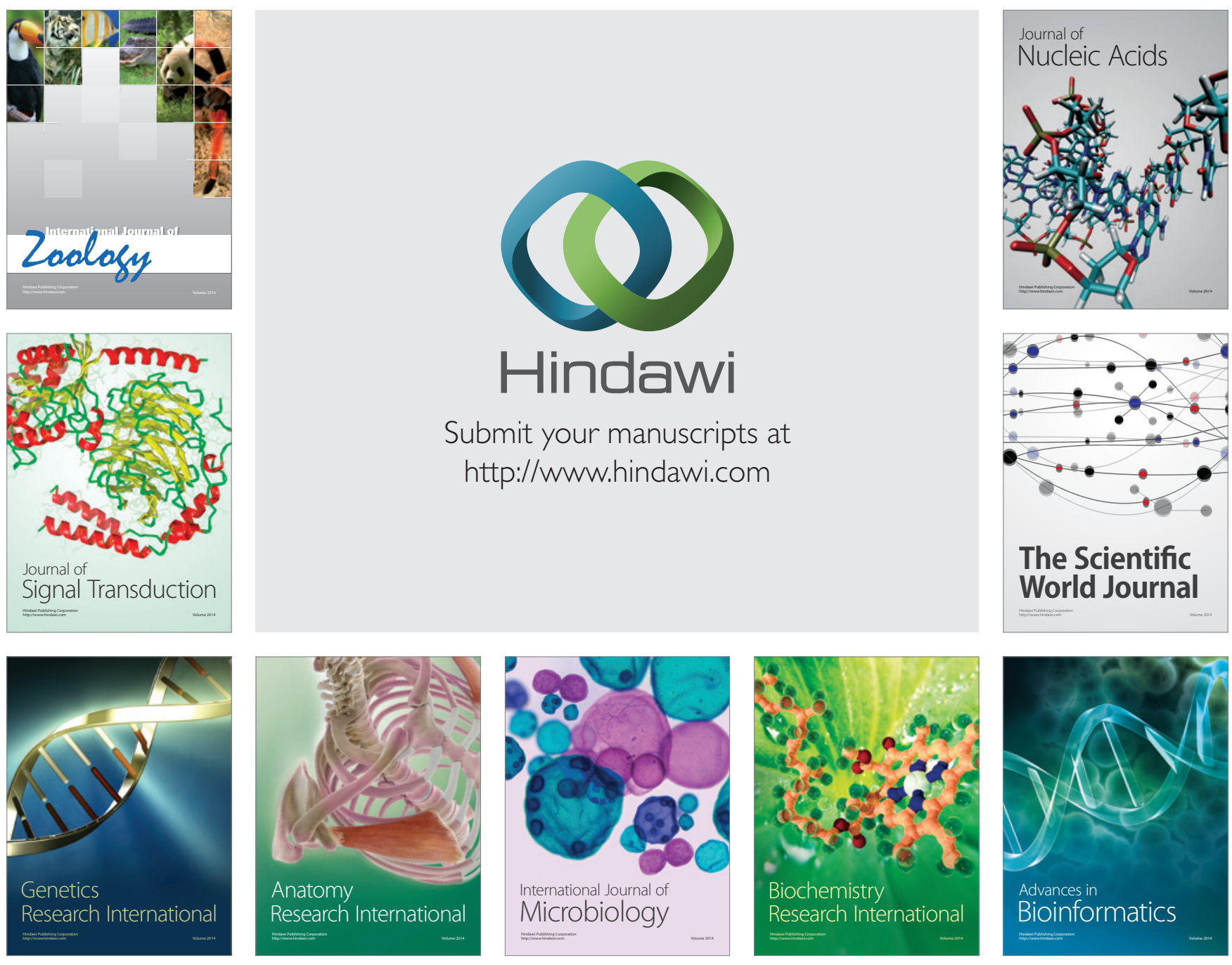

The Scientific World Journal
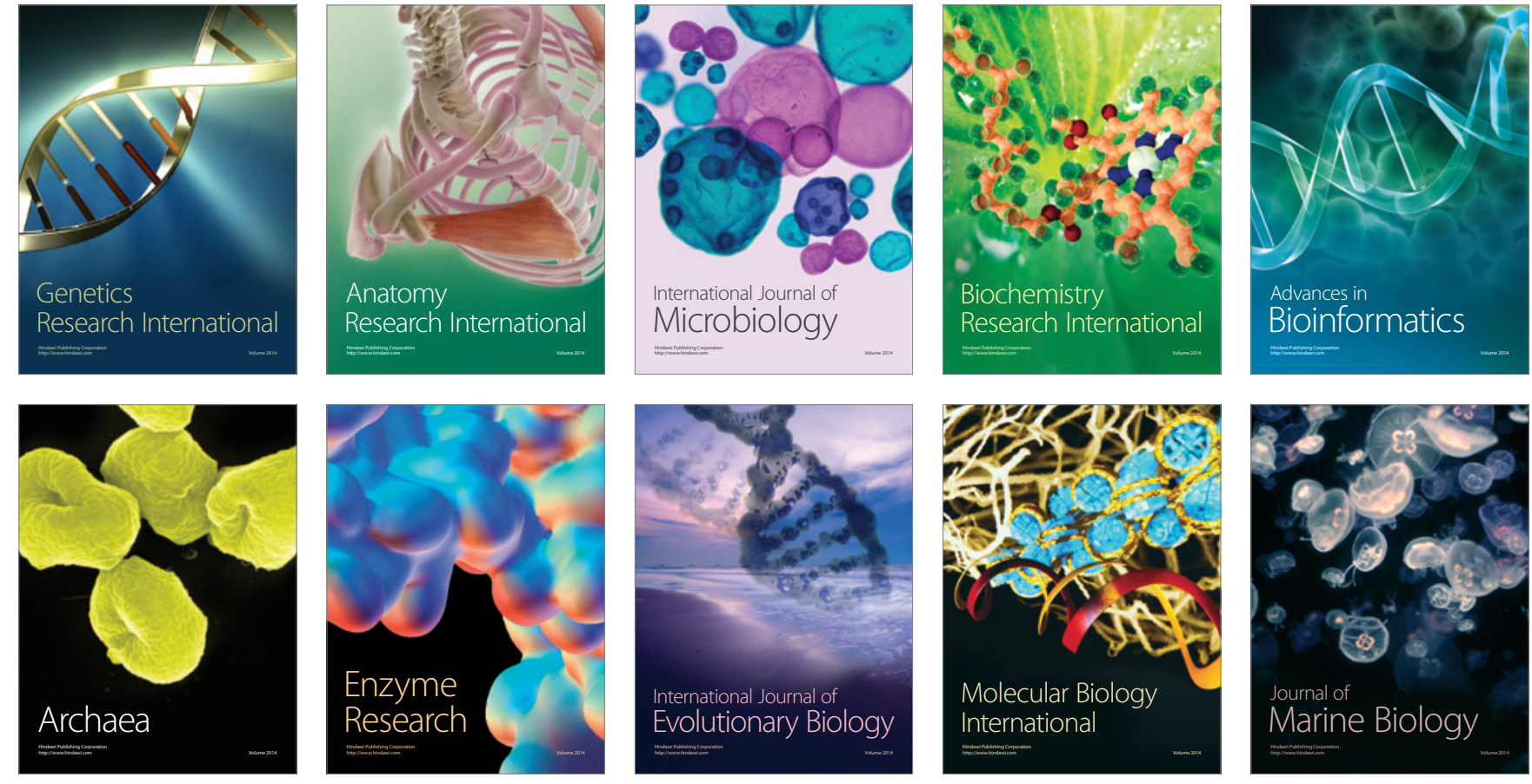